\title{
Consumption along the Life Cycle: How Different is Housing?
}

\author{
Fang Yang* \\ University of Minnesota
}

This version: Jan. 2005

\begin{abstract}
This paper develops a quantitative dynamic general equilibrium model of life cycle behavior, which distinguishes between housing and non-housing consumption and among real estate wealth and financial wealth. Households face uninsurable labor income risk and uncertain lifetimes, have an operative bequest motive, must hold a positive net wealth position, and pay transaction costs when trading houses. The model is able to match a key feature of the data: while the life time consumption profile of non-housing is hump shaped, the one for housing is monotonically increasing and then rather flat. The model is realistically calibrated to US data, and the quantitative relevance of the transaction costs, borrowing constraints and bequest motives in determining this pattern is investigated. I find that while borrowing constraints are essential at explaining the accumulating of housing assets in the early life, the existence of transaction costs is crucial to explain the slow downsizing of housing profile in the later life. The bequest motives plays a role in determining total life time wealth, but not its life cycle evolution.
\end{abstract}

*All comments are welcome to fyang@econ.umn.edu. I would like to thank Michele Boldrin, Marco Cagetti, V. V. Chari, Mariacristina De Nardi, Zvi Eckstein, Larry Jones, seminar participator at 2004 Venice Summer Institute for helpful comments and suggestions. I am grateful to Michele Boldrin and Mariacristina De Nardi for their advice. All remaining errors are my own. 


\section{Introduction}

The house is the single largest expenditure made by consumers over their life time. The median household has a house which is valued about twice their annual income. For non-homeowners, saving to purchase a house is one of the most common reason given for assets accumulation in young households (Engelhardt (1996)).

Understanding the life-cycle pattern of consumption and assets allocation behavior is crucial for policy analysis. Since individual behavior changes over the life cycle, the effect of policy on each age group changes too. Identifying a model capable of explaining the consumption decisions allows a better understanding of the effect of policy reforms. In addition, the lifecycle pattern of consumption of non-housing may be closely related to the life-cycle pattern of consumption of housing. Thus the abstraction from housing may bias the study of life cycle consumption and assets accumulation behavior.

Micro data shows two different patterns of consumption of housing and non-housing goods over the life cycle. My estimation from Consumer Expenditure Survey (CEX) shows that consumption expenditure of non-housing goods is hump-shaped over the life cycle: it starts low early in life, rises considerably around middle age, and then falls at more advanced ages. While the expenditure on non-housing is hump-shaped over the life cycle, my estimation of housing stock from Survey of Consumer Finances (SCF) shows that the household holdings of the stock of housing are not hump-shaped: life time profile of housing stock is monotonically increasing and then rather flat. This confirms Fernandez-Villaverde and Krueger (2002) who show that the peak of market valued housing service does not occur until late 50's, then decreases slightly, only to mildly increase towards the end of the life cycle. The different patterns of housing and non-housing consumption along the life cycle thus contradicts a key prediction of the standard life-cycle model without market frictions: the ratio of housing and non-housing consumption should not be age-dependent. That is to say, consumption of housing should follow the same pattern as non-housing consumption.

These stylized facts of life cycle consumption motivate asking whether a few modifications of the basic life-cycle framework might produce the life cycle consumption profiles that are more closely resemble the US life cycle consumption profiles. To answer this question, I construct a general equilibrium 
life cycle model of consumption and saving that departs from a standard lifecycle model in one key aspect: it introduces consumer durables (similarly to Fernandez-Villaverde and Krueger (2001)). Housing have dual roles: they provides utility as consumption goods, and can be used as collateral. In this framework, households face several market frictions: uninsurable labor income risk, uncertain lifetime, borrowing constraints, and housing transaction costs. In this environment households save to self-insure against labor earnings shocks and life-span risk, for retirement, to enjoy services from housings, and possibly to leave bequests to their children.

The goal is to show that a plausibly parameterized version of my model can quantitatively explain the empirical findings. That the interaction between housing (which can be used as collateral) and borrowing constraints leads to accumulation of housings early in the life, and transaction costs tend to slow the decumulation of the stock of housings late life in life.

Due to the heterogeneity of housing and the spatial fixity of housing, both potential buyers and sellers in the housing market are forced to spend considerate amount of time and resource to acquire information about the value of a specific housing units. As a consequence, there are considerable implicit and explicit search costs associated with a moving (Chinloy 1980). These include opportunity cost of time associated with market search, brokerage and agent fee, recording fee, legal fee, origination fee. Besides, households have to physically move to a new house, which entail moving costs and psychologically costs of breaking neighborhood attachments (Smith, Rosen, Fallis (1988)). Following Grossman and Laroque (1990), I assume that households incur adjustment costs when altering the holding of houses, but financial assets can be bought and sold without any costs and consumption of nonhousing goods can also be adjusted without any costs. When choosing a new house, forward-looking household takes into account the effect of adjustment costs. Because of large search and transaction costs associated with trading a house, households do not respond to changes such as income until the present value of expected benefits from changing the quantity of housing consumed exceeds the associated transaction costs. Therefore consumption of housing service will be constant at a new level until it is worthwhile to incur the adjustment costs again. Thus the home purchase decision is infrequent endogenously.

Among the literature that studies housing and durable goods. DiazGimenez, Prescott, Fitzgerald, and Alvarez (1992) study the effect of alternative monetary policy in a model with durables. Diaz-Gimenez and Puch study the effect of different borrowing constraints on welfare. FernandezVillaverde and Krueger (2002) document that consumption expenditure is 
hump-shaped over the life cycle: it starts low early in life, rises considerably around middle age, and then falls at more advanced ages. This pattern holds for consumption expenditures on both non-durables and durables, even after controlling for the demographic characteristics of the households. Fernandez-Villaverde and Krueger (2001) show that a plausibly parameterized version of the life cycle model with endogenous borrowing constraints can explain the hump-shaped pattern of durable and nondurable consumption expenditure. Their model can't generate the slow decumulation of housings. Diaz and Luengo-Prado (2003) investigate the effects of illiquid durable goods and collateral credit on the level of precautionary saving, the shape of wealth distribution and on household wealth composition. Their framework assumes infinitely-lived households, and hence cannot be used to study the life cycle pattern of consumption. Gruber and Martin (2003) use a model similar to Diaz and Luengo-Prado (2003) and study the effect of changes in transaction costs on precautionary saving and on wealth distribution. My model takes this dimension into consideration.

Although my focus is the life cycle pattern of consumption of housing and non-housing, my model also has implications for the optimal portfolios allocation between financial assets and housings at each point of life cycle. Along this dimension, this paper is related to the strands of optimal portfolio choice in the presence of consumer durables. Grossman and Laroque (1990) analyze optimal consumption and portfolio in a context in which utility is derived only from an illiquid durable goods. They show that even modest transaction costs associated with adjusting quantity of durable goods will prevent the household from equaling the marginal utility of consumption with the marginal utility of wealth and therefore cause the consumption based CAPM to fail. Flavin and Yamashita (2000) assume a exogenous housing consumption level and find that consumption demand for housing is likely to create a highly leveraged position for younger households. In contrast with most models of household portfolio choice that explicitly include the presence of housing, I model the life cycle in a general equilibrium setting.

Among the literature that studies elderly housing equity, little evidence is found that elderly are drawing down their housing wealth. Instead, home ownership continues to be high in very old age and home equity does not appear to fall with age. Venti and Wise (1991) and (2001) show that elderly rarely spend down their housing equity at retirement. Merril (1984) and Venti and Wise (1991) found that, when the elderly move, they are as likely to move into a larger house than a smaller house. The evidence from existing literature shows than homeowners don't use housing wealth to 
support a higher level of non-housing consumption in retirement. Sheiner and Weil (1992) find that the very elderly reduce housing wealth, and there is a strong tendency to reduce housing equity in the period immediately preceding death.

Among the literature on life cycle general equilibrium models that incorporate a bequest motive, De Nardi (2003) constructs a model in which parents and children are linked by accidental and voluntary bequests and by earning ability and shows that voluntary bequests can explain the emergence of large estate and the long upper tail of the wealth distribution. Ocampo and Yuki (2002) use a similar framework to investigate the quantitative importance of different saving motives on wealth inequality and aggregate capital accumulation. Laitner (2001) uses an Overlapping Generations Model with both life-cycle saving and altruistic bequest to match the high degree of wealth concentration and analysis the impact of changes in national debt and social security on capital output ratio.

The paper is organized as follows. In section 2, I present some empirical results from the CEX and SCF documenting households' consumption over the life cycle. In section 3, I present my model and define the equilibrium. The calibration of the model is presented in section 4 . In section $5, \mathrm{I}$ present the quantitative results of the benchmark model and investigate the quantitative importance of the transaction costs, borrowing constraints and bequest motives. Section 6 conduct sensitivity analysis. Brief concluding remarks are provided in section 7 . Technical discussions about my calibration of aggregate variables, the computational algorithm and definition of invariant distribution and bequest distribution are provided in the appendix.

\section{Empirical Findings}

This section presents our empirical findings on consumption of non-housing and housing over the life cycle. We first study the life cycle profile of consumption of non-housing goods using data from the CEX. We deal explicitly with the problem of household size. Then we look at the life cycle profile of housing stock derived from the SCF, controlling for cohort and time effects.

The CEX is carried out by the Bureau of the Census, and is a random sample rotating panel that contains information on demographic characteristics, inventory of major housing and consumption expenditure. Each quarter about 5000 households participate in the survey. The survey consists of a quarterly Interview Survey in which each consumer unit in the sample is interviewed every three months over a 15-month period, and a 
Diary Survey completed by the sample consumer units for two consecutive one-week periods. The Interview Survey was designed to collect data on major items of expense, household characteristics, and income. The expenditures covered by the survey are those that respondents can recall fairly accurately for three months or longer. The Diary Survey record consumer units' self-reported daily purchase over two consecutive one-week periods. CEX is the only micro-level data set reporting comprehensive measure of consumption expenditure for a large cross-section of household in the US. It has been commonly used in the consumption literature to study consumption behavior.

I use 2001 CEX data to estimate life cycle profiles of non-housing consumption expenditures ${ }^{1}$. I take each household as one observation and use the age of the reference person regardless of the person's gender. Only households with positive income and consumption expenditure are selected. The data on "expenditure on non-housing consumption" include food, alcohol beverages, tobacco, utilities, personal care, household operations, public transportation, gas and motor oil, vehicles, books and electronic equipment, apparel, out-of-pocket health and education expenditure, entertainment and miscellaneous expenditures.

Figure 2.1 plots total quarterly expenditure on non-housing goods against household age. Estimated quarterly consumption increases from around $\$ 16,500$ to nearly $\$ 32,900$, and then decrease to about $\$ 12,300$. The peak is reached at age forty five. The size of the hump, measured by the ratio of consumption expenditure between at the peak and at the beginning of life cycle, is around 1.9. It is clear that consumption expenditure on non-housing goods declines dramatically in the later age. The pattern of non-housing consumption is similar to pattern of nondurable consumption reported in Fernandez-Villaverde and Krueger (2002).

Households of different size plausibly face different marginal utilities from the same consumption expenditure. Consequently, changes in household size might explain the hump in consumption (Attanasio and Weber (1995) and Attanasio et al. (1999)). Thus I adjust for the changing of household size along the life cycle using equivalence scales which quantify the change in consumption expenditure needed to keep welfare of family constant, regardless of its size (see for example Zeldes (1989), Blundell, Browning and

\footnotetext{
${ }^{1}$ Fernandez-Villaverde and Krueger (2002) use the CEX Data to construct a pseudo panel. They find that the results from using pseudopanel and controlling for cohort and time effects is similar to results from using cross-section. Thus for simplicity I estimate using cross-section CEX instead.
} 
Meghir (1994),Fernandez-Villaverde and Krueger (2002)). I uses the following equivalence scales as in Fernandez-Villaverde and Krueger (2002), which is close to the equivalence scales of the Department of Health and Human Services (Federal Register (1991)), the estimates of Johnson and Garner (1995) and to the constant-elasticity equivalence scales used by Atkinson et al. (1995), Buhmann et al. (1988) and Johnson and Smeeding (1998), among others.

$\begin{array}{llllll}\text { Family Size } & 1 & 2 & 3 & 4 & 5 \\ \text { equivalence scales } & 1 & 1.34 & 1.65 & 1.97 & 2.27\end{array}$

Table 2.1 Equivalence scales

I take non-housing consumption expenditure from the CEX and then I use the demographic information of the household to obtain the equivalence scales and adjust consumption by equivalence scales. Figure 2.2 plots the estimated life cycle profiles of quarterly expenditure on non-housing goods. Adjusted quarterly consumption increases from around $\$ 12,800$ to nearly $\$ 21,000$ and then decreases to about $\$ 10,800$. Also, the peak in adjusted consumption is postponed, close to the age of fifty-five. The size of the hump measured by the ratio of consumption expenditure between at the peak and at the beginning of life cycle is around 1.3. It is clear that consumption expenditure on non-housing goods declines dramatically in the later age.

The CEX does not report a measure of consumption services from housing, except that the survey asks for an estimate of the present monthly rental value of the owned residence. Figure 2.3 plots the estimated life cycle profile of housing consumption for household that own houses, with and without controlling for cohort effects and time effects ${ }^{2}$. This figure shows that, when controlling for time and cohort effects, the peak of (marked valued) housing service does not occur until age fifty five, then decreases slightly, and then flattens out until the end of the life cycle.

Figure 2.4 plots the estimated life cycle profiles of housing services deflated by equivalence scales, which turns out to be very similar to the profile not adjusted for equivalence scales. The later increase in the adjusted rental value of the home is due to the reduction in household size when one of the spouses dies.

To test the robustness of profile of housing consumption, I use the SCF data to estimate life cycle profiles of housing stock, and controlling for cohort

\footnotetext{
${ }^{2}$ I would like to thank Fernandez-Villaverde and Krueger for providing me with their estimation results of housing rental value along the life cycle.
} 
and time effects. The SCF, sponsored by the Federal Reserve Board and conducted by the University of Michigan and the National Opinion Research Center, has become the main source of microeconomics data on wealth for the U.S.. It is conducted triennially and collects detailed information about wealth for a cross section of households, and unfortunately, it only includes a limited, small, panel between 1983 and 1989. To provide a more accurate measure of wealth inequality, the SCF over-samples rich households by including samples drawn from tax records. The "dual frame"sample design provides representation of both broadly-held item, such as homes and vehicles, and other assets held disproportionately by the wealthy such as stocks and bonds.

I constructed synthetic cohort by using six waves of the SCF (1983-1998). I use the age of the reference person to define 10 cohorts with a length of 5 years, starting from age 20, and follow then through the whole sample, generating a panel. For example, the households born between 1958-1963 were $20-25$ years old in 1983. The pseudo panel approach treats the 23-28 year old households in the 1983 wave as if they were the same people as the 20-25 year old in the 1989 data. The grouping in cells is done to keep the number of observations relatively big, most of the cells I use have 50 to 350 observations. Housing asset is the value of the primary residential house. Housing assets are deflated to be in 1983 dollars using the CPI price index. I control for cohort, time, and age effects by employing a semi-nonparametric partially linear model. Details of estimation are available in Yang (2004).

Figure 2.5 plot mean housing stock against household head's age. we observe that mean housing stock increases rapidly in the early life. We do not find evidence of downsizing of housing stock in the later life. This confirms with Fernandez-Villaverde and Krueger (2002) who estimate the equivalent housing rental value using CEX data.

The finding that elderly household do not decumulate their housing consumption is consistent with the empirical findings from other literature. Feinstein and McFadden(1989) suggest that more than one-third of elderly households resides in dwellings with at least three more rooms than the number of inhabitants, and are thus overconsuming housing services.

The different patterns of housing and non-housing consumption along the life cycle thus contradicts a key prediction of the standard life-cycle model without market frictions: the ratio of housing and non-housing consumption should not be age-dependent. That is to say, consumption of housing should follow the same pattern as non-housing consumption. 


\section{The Model}

The economy is a discrete-time, overlapping-generations world with income uncertainty and lifetime uncertainty. Compared with a standard life-cycle economy, this model introduce housing. Housing have dual roles: they provides utility as consumption goods, and can be used as collateral thus the borrowing limit of each household depends on the value of her housing stock. Trading of housing incurs large transaction costs. At age 20 each person enters the model and starts consuming and working. At age 30 the consumer procreates. After retirement the agent no longer works but receives interest from accumulated assets. There is no annuity markets. There is no government in this economy. Also for simplicity, I assume there is no housing rental market.

\subsection{Demographics}

During each model period, which is 5 years long, a continuum of people is born. Since there are no intervivos transfers in this model economy, all agents start their working life with no financial assets and no housings. I denote age $t=1$ as 20 years old, age $t=2$ as 25 years old, and so on. At the beginning of period 3, the agent's children are born, and four periods later (when the agent is 50 years old) the children are 20 and start working. The agents are retired at $t=10$ (i.e., when they are 65 years old) and die for sure by the end of age $T=12$ (i.e., before turning 80 years old). From $t=10$ (i.e., when they are 65 years old), each person faces a positive probability of dying giving by $\left(1-p_{t}\right)$. The probability of dying is exogenous and independent of other household characteristics. The population grows at rate $\mathrm{n}$. Since the demographic patterns are stable, agents at age t make up a constant fraction of the population at any point in time. Figure 3.1 illustrates the demographics in the model.

\subsection{Technology}

There is one type of good produced according to the aggregate production function $F(K ; L)$ where $K$ is the aggregate capital stock and $L$ is the aggregate labor input. I assume a standard Cobb-Douglas functional form. In equilibrium the number of firms is indeterminate, and without loss of generality I assume that there is a single representative firm. The final good can be either consumed or invested into physical capital or transformed into housings. Let $H$ denote the aggregate stock of housings in current period, 
$C$ the aggregate consumption of non-housing, $I^{h}$ the aggregate investment on housing, $I$ the aggregate investment on physical capital goods, $T$ the total transaction costs for housing, and $\delta$ and $\delta^{d}$ are the depreciation rates on physical capital and housings, respectively. The aggregate resource constraints are:

$$
\begin{aligned}
C+I+I^{h}+T & =Y \\
K^{\prime} & =I+(1-\delta) K \\
H^{\prime} & =I^{h}+\left(1-\delta^{d}\right) H \\
Y & =F(K ; L)=A K^{\rho} L^{1-\rho} .
\end{aligned}
$$

Households rent capital and efficient labor units to the representative firm each period and receive rental income at the interest rate $r$ and wage income at the wage rate $w$.

\subsection{Timing and information}

Households observe their idiosyncratic shocks and possibly receive some inheritance from their parents. Then labor and capital is supplied to firms and production takes place. Next, the households receive factor payments and make their consumption and asset allocation decisions. housings stock are not transferred until the end of the period. Therefore the addition or subtraction to the stock will not influence the present period service flow. Finally uncertainty about early death is revealed.

The idiosyncratic labor productivity status is private information and the survival status is public information. I assume that children can observe their parent's productivity when the parent is 50 and the children are 20.

There are no state contingent markets for the household specific shock. The only insurance market is a one-period bonds market.

\subsection{Consumer's maximization problem}

\subsubsection{A. Preferences}

Individuals derive utility from consumption of non-housing, $c$, and from the service flow of the housing, $h$ and from bequests transferred to their children upon death. The service flow of housing is assumed to be proportional to the housing stock and by choice of units, the proportional factor is normalized to be 1 . Thus the utility function is written as a function of the housing 
stock. Preference are assume to be time separable, with a constant discount factor. The momentary utility function from consumption is of the constant relative-risk aversion class given by

$$
U(c, h)=\frac{g(c, h)^{1-\eta}-1}{1-\eta} .
$$

I choose $g(c, h)=\left(a(c)^{\sigma}+(1-a)(h+\varepsilon)^{\sigma}\right)^{\frac{1}{\sigma}}$, where $h$ is the service flow from housing, which is assumed to be equal to the value of housing stock. When $\sigma=0$, the function $g$ takes a Cobb-Douglas form. I add a positive number $\varepsilon$ so that utility function is well defined at $h=0$ for $\sigma=0$. The term $\varepsilon$ is small enough that it doesn't affect the results.

Following De Nardi (2004), the utility from bequest is denoted by

$$
\phi(b)=\phi_{1}\left(1+b / \phi_{2}\right)^{1-\eta} .
$$

The term $\phi_{1}$ reflects the parent's concern about leaving bequests to her children, while $\phi_{2}$ measures the extent to which bequests are luxury goods.

Note that this form of "impure" bequest motive implies that an individual cares about the bequests left to his children, but not about consumption of his children. If an individual is assumed to care about utility of her children, and both parents and kids are maximizing utility as different units, the strategic interaction across generations complicates the analysis.

\subsubsection{Transaction costs}

I consider non-convex costs of adjustments in the stock of housings. A household can buy a stock of any size, but once the stock has been bought, it is illiquid. I force the household to pay adjustment costs every time the household sells and buy new house. Right after consuming the services, the stock depreciates at the rate $\delta^{d}$. This formation of transaction costs allow households to change their level of housing consumption by undertaking housing renovation up to a fraction of $\mu_{2}$ the value of house or by allowing depreciation up to a fraction of $\mu_{1}$ the value of house as an alternative to moving. If the households let the housing depreciate by more that a faction $\mu_{1}$ of the value, or if the value of the stock increases by more that a faction $\mu_{2}$ of the value, I assume that the stock has been sold. In those cases, the household has to pay the adjustment costs as a fraction $\rho_{1}$ of its selling value and $\rho_{2}$ of its buying value. The specification of the adjustment costs is: 


$$
\tau\left(h, h^{\prime}\right)=\left\{\begin{array}{cc}
0 & \text { if } h^{\prime} \subset\left[\left(1-\mu_{1}\right) h,\left(1+\mu_{2}\right) h\right] \\
\rho_{1} h+\rho_{2} h^{\prime} & \text { otherwise }
\end{array}\right.
$$

As Gruber and Martin (2003) point out, the transaction costs structure that best capture the structure of U.S. housing market is one which incorporates both fixed and proportional transaction costs. The fee on the sales of the existing stocks of housing is a fixed costs since the size of transaction is not in the household's current choice set. The fee on the purchase of new housing is a proportional transaction cost. Thus the treatment of transaction costs capture the structure of U.S. housing market.

\subsubsection{Borrowing constraints}

I assume that only collateralized credit is available and that the borrowing interest rate, mortgage interest rate and deposit interest rate are all equal. This implies that mortgages and deposits are perfect substitutes. I use $a_{t}$ to denote the net asset position. To buy housing households must satisfy a minimum down payment requirement as a fraction $\theta$ of their value. housings also serve as collateral for loans (through home equity loans or refinancing) up to a fraction $(1-\theta)$. At any given period household asset must hence satisfy:

$$
a \geq-(1-\theta) h,
$$

and household's net worth is thus always non-negative. Notice in this case, a household net worth is bounded below by her value of housing,

$$
a+h \geq \theta h .
$$

For a household without any housing stock, the borrowing constraint reduces to the standard form $a \geq 0$.

\subsubsection{Labor Productivity}

In this economy all agents of the same age face the same exogenous ageefficiency profile $\epsilon_{t}$. This profile is estimated from the data and recovers the fact that productive ability changes over the life cycle. Workers also face stochastic shocks to their productivity level. These shocks are represented by a Markov process defined on $(Y ; B(Y))$ and characterized by a transition function $Q_{y}$, where $Y \in R_{++}$and $B(Y)$ is the Boreal algebra on $\mathrm{Y}$. This Markov process is the same for all households. This implies that there is no 
aggregate uncertainty over the aggregate labor endowment although there is uncertainty at the individual level. The total productivity of a worker of age $t$ is given by the product of the worker's stochastic productivity in that period and the worker's deterministic efficiency index at the same age: $y_{t}$ $\epsilon_{t}$.

The parent's productivity shock at age 50 is transmitted to children at age 20 according to a transition function $Q_{y h}$, defined on $(Y ; B(Y))$. What the children inherit is only their first draw; from age 20 on, their productivity $y_{t}$ evolves stochastically according to $Q_{y}$.

For simplicity, I assume that children cannot observe directly their parent's assets, but only their parent's productivity when their parent is 50 and the children are 20, that is, the period when they leave the house and start working. Based on this information, children infer the size of the bequests they are likely to receive.

\subsubsection{The Household's Recursive Problem}

In the stationary equilibrium, the household's state variables are given by $(t, a, h, y, y p)$, which, respectively, denote the agent's age, financial assets and housing stock carried from the previous period, and the agent's productivity, respectively. The term yp denotes the value of the agent's parent's productivity at age 50 until the agent inherits and zero thereafter. When $y p$ is positive, it is used to compute the probability distribution on bequests that the household expects from the parent. When the agents have already inherited, yp is set to be 0 .

According to the demographic transitions, there are four cases depending on the possibility of inheritance and possibility of dying.

(i) From age $t=1$ to age $t=3$ (from 20 to 30 years of age), the agent works and survives with certainty until next period. Moreover, the agent does not expect to receive a bequest soon because his or her parent is younger than 65 and will survive at least one more period for sure. Since the law of motion of $y p$ is dictated by the death probability of the parent, for these sub periods $y p^{\prime}=y p$.

$$
V(t, a, h, y, y p)=\max _{c, a^{\prime}, h^{\prime}}\left\{U(c, h)+\beta E\left(V\left(t+1, a^{\prime}, h^{\prime}, y^{\prime}, y p\right)\right)\right\}
$$

subject to 


$$
\begin{aligned}
& c+a^{\prime}+h^{\prime}+\tau\left(h^{\prime}, h\right) \\
= & w \varepsilon y+(1+r) a+\left(1-\delta^{d}\right) h \\
a^{\prime} \geq & -(1-\theta) h^{\prime} \\
c \geq & 0, h^{\prime} \geq 0 .
\end{aligned}
$$

At any sub period, the agent's resource are derived from asset holdings, $a$, labor endowment, $\varepsilon y$, housing stock holding, $h$. Assets holding pay a risk-free rate $r$ and labor receives a real wage $w$. Housing depreciates at rate $\delta^{d}$.

The evolution of $y$ is described by the transition function $Q_{y}$.

(ii) From $t=4$ to $t=6$ (from 35 to 45 years of age), the worker survives for sure until the next period. However, the agent's parent is at least 65 years old and faces a positive probability of dying at any period; hence, a bequest might be received at the beginning of the next period. The conditional distribution of bequest a person of state $x$ expects in case of parental death is denoted by $\mu_{b}(x ;:)$. In equilibrium this distribution must be consistent with the parent's behavior. Since the evolution of the state variable $y p$ is dictated by the death process of the parent, $y p^{\prime}$ jumps to zero with probability $1-p_{t+6}$. Let $I_{y p>0}$ be the indicator function for $y p>0$; it is one if $y p>0$ and zero otherwise.

$$
V(t, a, h, y, y p)=\max _{c, a^{+}, h}\left\{U(c, h)+\beta E\left(V\left(t+1, a^{\prime}, h^{\prime}, y^{\prime}, y p^{\prime}\right)\right)\right\}
$$

subject to

$$
\begin{aligned}
& c+a^{+}+h^{\prime}+\tau\left(h^{\prime}, h\right) \\
= & w \varepsilon y+(1+r) a+\left(1-\delta^{d}\right) h \\
a^{+} \geq & -(1-\theta) h^{\prime} \\
a^{\prime}= & a^{+}+b^{\prime} I_{y p>0} I_{y p^{\prime}=0} \\
c \geq & 0, h^{\prime} \geq 0
\end{aligned}
$$

where $a^{+}$denotes the financial assets at the end of the period before receiving bequest.

(iii) The sub periods $t=7$ to $t=9$ (from 50 to 60 years of age) is the periods before retirement, during which no more inheritances are expected 
because the agent's parent is already dead by that time. Therefore $y p$ is not in the state space any more. The agent does not face any survival uncertainty.

$$
V(t, a, h, y)=\max _{c, a^{\prime}, h^{\prime}}\left\{U(c, h)+\beta E\left(V\left(t+1, a^{\prime}, h^{\prime}, y^{\prime}\right)\right)\right\}
$$

subject to

$$
\begin{aligned}
& c+a^{\prime}+h^{\prime}+\tau\left(h^{\prime}, h\right) \\
= & w \varepsilon y+(1+r) a+\left(1-\delta^{d}\right) h \\
a^{\prime} \geq & -(1-\theta) h^{\prime} \\
c \geq & 0, h^{\prime} \geq 0 .
\end{aligned}
$$

(iv) From $t=10$ to $t=12$ (from 65 to 75 years of age), the agent does not work and does not inherit any more, but faces a positive probability of dying. In case of death, the agent derives utility from bequeathing his or her assets. When parents die, their housings are sold automatically and transaction costs are incurred.

$$
V(t, a, h)=\max _{c, a^{\prime}, h^{\prime}}\left\{U(c, h)+\beta p_{t}\left(V\left(t+1, a^{\prime}, h^{\prime}\right)\right)+\left(1-p_{t}\right) \phi(b)\right\}
$$

subject to

$$
\begin{aligned}
c+a^{\prime}+h^{\prime}+\tau\left(h^{\prime}, h\right) & =(1+r) a+\left(1-\delta^{d}\right) h \\
a^{\prime} & \geq-(1-\theta) h^{\prime} \\
c & \geq 0, h^{\prime} \geq 0,
\end{aligned}
$$

where

$$
b=a^{\prime}+h^{\prime}-\rho_{1} h^{\prime} .
$$

The terminal value $V\left(T+1, a^{\prime}, h^{\prime}\right)$ is set to be 0 for every $a^{\prime}, h^{\prime}$.

\subsubsection{Definition of Stationary Equilibrium}

In this economy, agents differ in term of their age, assets holding, housing stock, and idiosyncratic labor productivity and also parent's labor productivity at age 50 . Each agents state is denoted by $x$. 
I focus on an equilibrium concept where factor prices are constant over time and where capital, labor are constant in per capita terms. In addition, the age-wealth distribution is stationary over time. Equilibria are described at follows.

Definition: A stationary equilibrium is given by an interest rate $r$ and a wage rate $w$; value functions $V(x)$, allocations $c(x), a^{\prime}(x), h^{\prime}(x)$; a family of probability distributions for bequests $\mu_{b}(x ;:)$ for a person with state $x$; and a constant distribution of people over the state variables $x: m^{*}(x)$, such that the following conditions hold:

(i) Given the interest rate, the wage, and the expected bequest distribution, the functions $V(x), c(x), a^{\prime}(x)$, and $h^{\prime}(x)$ solve the above described maximization problem for a household with state variables $x$.

(ii) $m^{*}$ is the invariant distribution of households over the state variables for this economy. I normalize $m^{*}$ so that $m^{*}(X)=1$, which implies that $m^{*}(\chi)$ is the fraction of people alive that are in a state $\chi$. Appendix discribe the calculaton of invariant distribution in greater details.

(iii) All markets clear.

$$
\begin{aligned}
K & =\int a d m^{*}(x) \\
H & =\int h d m^{*}(x) \\
C & =\int c d m^{*}(x) \\
L & =\int \epsilon y d m^{*}(x) \\
T & =\int \tau\left(h^{\prime}, h\right) d m^{*}(x) \\
F(K ; L) & =C+K-(1-\delta) K+H-\left(\left(1-\delta^{d}\right) H-T\right)
\end{aligned}
$$

(iv) The price of each factor is equal to its marginal product.

$$
\begin{aligned}
r & =F_{1}(K, L)-\delta \\
w & =F_{2}(K, L)
\end{aligned}
$$

(v) The family of expected bequest distributions is consistent with the bequests that are actually left by the parents. Appendix discribe the consistency of bequest distribution in greater details. 


\section{Calibration}

Some parameters used in the benchmark model are based on estimations by other studies. The remaining parameters are chosen so that the model generated data match a given set of targets. Since one period in my model corresponds to 5 years in real life, I adjust parameters accordingly.

The rates of population growth, $n$, are set to the average population growth from 1950 to 1997 from Economic Report of the President (1998).

I construct measures of output $Y$, capital $K$ and housings $H$ and their investment counterparts according to my model. I use data from the National Income and Product Accounts and the Fixed Assets Tables both form the Bureau of Economic Analysis for the year 1954-1999. The aggregate ratios for US economy are calibrated to explicitly consider the existence of housing that comprise residential assets. Output is defined as measured GDP minus housing services to be consistent with the model. I define capital as the sum of nonresidential private and government fixed assets plus the stock of inventories. Investment in capital, $I$ is defined accordingly. The stock of housings is defined as the stock of private residential assets. Investment in housings, $I^{h}$, is constructed accordingly. The term $\alpha$ is the share of income that goes to capital, which I fix at 0.226. This capital share (non residential stock of capital) is much lower than in other calibrations, which abstract from housing. I choose $\delta^{d}$ to be 0.0700 and $\delta$ to be 0.0294 . The appendix explains the rationale behind these choices in details.

$\sigma$ governs the elasticity of substitution between housing and non-housing. Ogaki and Reinhart (1998) use aggregate data and a similar specification, and obtain an estimated $\sigma=0.145$, not significantly different from zero. I thus choose $\sigma$ to be 0 so that the monentary utility function $g(c, h)$ takes

the Cobb-Douglas form. I conduct sensitivity analysis and the results does not depend on the special value $\sigma$.

The deterministic $\epsilon_{t}$ age-profile of the unconditional mean of labor productivity is taken from Hansen (1993). Since I impose mandatory retirement at the age of 65 , I take $\epsilon_{t}=0$ for $t>9$.

Since one of my main interest is to look at how transaction costs on housing stock adjustment affect consumption and saving decisions, one key calibration is the type of transaction costs that I choose. Smith, Rosen, Fallis (1988) estimate the transaction costs of changing houses, including searching, legal costs, cost of readjusting home, and psychic costs from disruption. Their estimation is approximately 8-10 percentage the unit being changed. Gruber and Martin (2003) estimate the reallocation cost of tax and agency costs from CEX and find the median household pays costs of the 
order of 7 percent to sell their house and 2.5 percent to purchase. Martin (2002) finds that the monetary costs of buying a new home, which include agent fee, transfer fee, appraisal and inspection fee, range on average from 7 to 11 percent of purchase price of a home. In my simulation, I restrict myself to symmetric costs and choose transaction costs from sale to be $\rho_{1}=4 \%$, and transaction costs from purchase to be $\rho_{2}=4 \%$. These value are much lower than the transaction costs reported above therefore it serve as a low limit of the effect of transaction costs.

The down payment ratio $\theta$ is set to be 0.2 , which is commonly used in housing literature. Recently some households are allowed to purchase a house without much initial wealth. But as Caplin et. al. (1997) argue that "it is almost impossible for a household to purchase a home without available liquid assets of at least $10 \%$ of the home's value". Also what is crucial for my model is the assumption that young and poor household can not borrow beyond the liquidation value of their collateral. Therefore, I choose a high down payment ratio despite the recent decline of down payment ratio. I conduct sensitivity analysis on down payment ratio later.

The $p_{t}$ 's are the vectors of conditional survival probabilities for people older than 65 . In the calibration of the US economy, I use the mortality probabilities of people born in 1965 provided by Bell, Wade, and Goss (1992).

The Markov process of worker's stochastic productivity is given by:

$$
\ln y_{t}=\rho_{y} \ln y_{t-1}+\mu_{t} \quad \mu_{t} \in N\left(0, \sigma_{y}^{2}\right) .
$$

The parent's productivity shock at age 50 is transmitted to children at age 20 according to the following transition function:

$$
\ln y_{t}=\rho_{y} \ln y_{h, t+6}+\nu_{t} \quad \nu_{t} \in N\left(0, \sigma_{y h}^{2}\right) .
$$

The logarithm of the productivity process is assumed to be an $\mathrm{AR}(1)$ with persistence $\rho_{y}$ and variance $\sigma_{y}^{2}$. These two parameters are estimated from Panel Study on Income Dynamics (PSID) data, aggregated over five years in order to be consistent with the model period (Altonji and Villanueva (2002))

The logarithm of the productivity inheritance process is also assumed to be an $\operatorname{AR}(1)$ with persistence $\rho_{y h}$ and variance $\sigma_{y h}^{2}$. I take $\rho_{y h}$ from Zimmerman (1992), and take $\sigma_{y h}^{2}$ to match a Gini coefficient of 0.44 for earnings.

I take risk aversion, $\eta$, to 1.5, from Attanasio et. al. (1999) and Gourinchas and Parker (2002), who estimate it from consumption data. This value is in the commonly used range (1-5) in the literature. 
The rate $r$ is the interest rate on capital, net of depreciation. Given the calibration for the US production function, this interest rate is endogenous for the United States, and turns out to be $3.17 \%$.

I choose the discount factor, $\beta$ to match the capital-output ratio. The parameter $a$ determines the share of consumption allocated to the nonhousing and is set to match the ratio of non-housing expenditure to housing stock.

I use $\phi_{1}$ to match bequest output ratio of $2.65 \%$ in the US simulation (Gale and Scholz(1994)). Since in my model output corresponds to GDP minus housing service, I adjust it accordingly. $\phi_{2}$ is chosen to match the ratio of average bequest left by single decedents at the lowest 90 th percentile over GDP per capita. According to Hurd and Smith (1999), the average bequest left by single decedents at the lowest 90th percentile was $\$ 180,000$ (Asset and Health Dynamics Among the Oldest Old (AHEAD) data sets, 1993-95). GDP per capita was $\$ 26.652$ (IMF web).

\section{$5 \quad$ Numerical results}

The benchmark economy allows for housing transaction costs and $\mu_{1}=\mu_{2}=$ 0 . That is to say, if the value of the stock increases or decreases, I assume that the stock has been sold. In this case, the household has to pay the adjustment costs as a fraction $\rho_{1}=4 \%$ of its selling value and $\rho_{2}=4 \%$ of its buying value. I then show the effect of transaction costs on the lifecycle profiles of of financial assets, total net worth, housing and nonhousing consumption by change parameters $\rho_{1}, \rho_{2}, \mu_{1}, \mu_{2}$. Some parameters are set so that the model-generated data match a given set of targets (see above).

\subsection{Benchmark}

\subsubsection{Aggregate Variables}

Table 5.1, column 3, reports values for the aggregate variables for my benchmark economy with transaction costs and bequest motives. These figures are in line with long-run averages for the US economy reported in column 2. The aggregate ratios for US economy are calibrated to explicitly consider the existence of housing that comprise residential assets. In the calibration, I use data from the National Income and Product Accounts (NIPA) and the Fixed Assets Tables (FAT) published by the Bureau of Economic Analysis for the year 1954-1999. 


\subsubsection{Wealth Distribution}

Table 5.2 reports values for the wealth distribution for my benchmark economy with transaction costs and bequest motives. I present quintile shares, top 10\%, 5\%,1\% and Gini coefficient for housing, net worth and financial assets. U.S. wealth Distribution is taken from Gruber and Martin (2004) who use $2001 \mathrm{SCF}$. In the data wealth is highly unevenly distributed with a Gini coefficient of 0.81 . The top $1 \%$ households hold $32 \%$ of the total wealth and the top $5 \%$ households hold $57 \%$ of the total wealth. Housing is more evenly distributed than net worth with a Gini coefficient of 0.64 . The top $1 \%$ households hold $12 \%$ of the total housing wealth and the top $5 \%$ households hold $31 \%$ of the total housing wealth. Financial assets is more unevenly distributed than net worth with a Gini coefficient of 1.18. The top $1 \%$ households hold $48 \%$ of the total financial wealth and the top $5 \%$ households hold $80 \%$ of the total financial wealth. The Gini coefficient of financial wealth is bigger than 1 since there are large number of homeowner with mortgages and negative financial positions (Notice that the bottom $20 \%$ hold a fraction of $-15 \%$ of the net financial wealth).

Benchmark model matches the wealth distribution of wealth, housing and financial wealth quite well, with the exception of top 1\%. It also replica the empirical finding that inequality in financial assets is much higher than housing. This is because households are allowed to borrow against housing so financial assets can be negative but the housing stock can not be. Also for households that are not borrowing constrained, the return of housing, marginal utility of housing, is decreasing, while the return to financial assets, the interest rate, is constant. Thus durable as the fraction of net worth is decreasing.

\subsubsection{Life Cycle Profiles}

Figure 5.1 and 5.2 show the average life-cycle profiles of financial assets, total net worth, non-housing consumption and housing consumption. All figures are normalized by the average household income. These average are obtained by integrating the policy function with respect to the equilibrium measure of agents, holding age fixed. For example, the average housing consumption by an agent at age $t$ is given by

$$
H=\int h(t, a, h, y, y p) m(\{t\} \times d a \times d h \times d y \times d y p)
$$

Figure 5.1 displays the evolution of wealth portfolio over the life cycle. Young agents tend to hold little wealth because they start with zero wealth 
and they expect to have much higher earning in the future. Therefore to smooth consumption, they do not hold much wealth. Early in life households borrow as much as possible to buy a house, and thus save in the form of housing. As time goes by, agents have built stock of housings and start to increase their holding of financial assets. The wealth holding peaks at age 65 , the year before retirement. After retirement, they start to dissave assets to finance consumption. Old agents discount the future at a higher rate since the survival probabilities are declining in age. This implies that the consumption profile is declining in the later age and hence little wealth is needed to finance consumption in the late age. Compared with data reported in Huggett (1996), the wealth profile and assets profile have a hump that are more pronounced. There are several reasons to explain the discrepancy. In my model, agents do not receive social security benefits therefore they have a even stronger motive to save for retirement and the wealth holding at retirement age is higher relative to the data. Second, since I abstract from health uncertainty or other shocks that could motivate precautionary assets holding in old age, old agents do not have a precautionary saving motives as they do in the data therefore they run down their assets more quickly that in the data.

Figure 5.2 compare the average life-cycle profiles of non-housing consumption and housing consumption in the model with the data. Non-housing consumption from the data refers to CEX non-housing consumption reported in figure 2.1. I adjust the data so that non-housing consumption at age 50 is the same in the data and the model ${ }^{3}$, and housing stock at age 55 is the same in the data and the model ${ }^{4}$. From figure 5.2, we see the hump shape of average nonhousing consumption, which peaks around age 50 . The nonhousing consumption at peak is $60 \%$ more than that of age 20 , which is similar the pattern reported in the data in section 2. After the peaks, nonhousing consumption decrease steadily with age. Facing an increasing future income profile, young agents would like to borrow to finance their current consumption but they are borrowing constrained. This explain why in the early life consumption path increases as income path does. As households age, they start to decrease their nonhousing consumption due to the

\footnotetext{
${ }^{3}$ I match the aggregate consumption in the model with this in the NIPA. Compared with NIPA, CEX underreport consumption by a fraction of 20-30\% (see Attanasio, Battistin and Ichimura. for detailed discussion). Thus I would need to adjust for the difference accordingly.

${ }^{4}$ Housing stock in the data refers to estimated monthly housing rental value (figure 2.3) from Fernandez-Villaverde and Krueger (2002). Since model only generate housing stock, I am allowed to adjust data to normalize housing service flow to stock.
} 
fact that time preference is higher than the interest rate and mortality rates are increasing along the life cycle.

The housing consumption profile in the model reproduces the empirical observed increase in the early age and slow-downsizing in the later age. Agents build their stock of housing earlier in life and compromise on consumption of nonhousing. Agents build up their highest housing stock at the age of 55, 5 years later than the peak of non-housing consumption. Elderly do not down size their stock of housing later in life. Instead, households choose to borrow against their financial assets to finance nonhousing consumption.

The introduction of transaction costs forces agents to reduce the frequency of transactions in the housing market. Agents make no change to the stock of the housing unless the wealth and housing stock is too unbalanced. Two retired agents with the same housing stock, age and different holding of nonhousing assets may choose the same level of housing stock next period, as long as the difference of non-housing assets is not large. The size of the inactive region is different according to agents age and income and also is affected by parameters such as the size of the transaction costs. Even for relatively small transaction costs, the inaction range is quite large. Figure 5.3 show the policy function of housing next period as a function of current holding of non-housing and housing stock for a 70-year-old agent. Giving current stock of housing, there is a wide range of non-housing assets that households do not adjust for their housing stock. The inactive region can be defined by two boundaries, $\left(a_{l}(h), a_{h}(h)\right)$. If a household with a housing stock of $h$ holds non-housing assets more than the upper boundary $a_{h}(h)$, the household will move to a bigger house next period and hold less fraction of non-housing assets in her wealth portfolio. If instead she holds non-housing assets less than the lower boundary $a_{l}(h)$, the household will move to a smaller house next period and hold more fraction of non-housing assets in her wealth portfolio. Figure 5.4 show the boundaries of the inactive region on the plane of current holding of non-housing and housing stock for 70-year-old agent and 65-year-old agent respectively. One reason that the inactive region for a 65 -year-old agent is smaller than a 70-year-old agent is because a 65 -year-old agent has a long life expectency which increases the benefit of changing housing. Since bequest is modeled as a luxury good, the utility function is not homothetic. Thus the policy functions are not necessarily homothetic and the boundaries are not strict lines.

The existence of transaction costs affect young agents and old agents differently. Young households facing increasing income profiles would like to purchase large houses but they would have to accumulate enough non- 
housing assets to pay the down-payment. As a result, they have to upsize their housing stock fairly often. As the households age and their income profile stabilize, households would keep their level of housing stock unchanged, giving that trading of housing stock would incur transaction costs. Old households are less likely to move than young household, since their could only consume the new house for a relatively short period of time. Table 5.3 shows the fraction of households moving at each the end of each period for each age group.

\begin{tabular}{llll} 
& \multicolumn{3}{c}{ Faction $(\%)$} \\
Age & Moving & Upsizing & Downsizing \\
25 & 82.925 & 82.579 & 0.346 \\
30 & 19.696 & 17.309 & 2.387 \\
35 & 18.201 & 14.053 & 4.148 \\
40 & 19.748 & 15.891 & 3.858 \\
45 & 20.084 & 15.152 & 4.932 \\
50 & 22.283 & 14.078 & 8.205 \\
55 & 19.040 & 9.189 & 9.851 \\
60 & 17.110 & 6.643 & 10.467 \\
65 & 5.041 & 0.139 & 4.902 \\
70 & 2.702 & 0.080 & 2.621 \\
75 & 0 & 0 & 0
\end{tabular}

Table 5.3 Fraction of households moving at each age

\subsection{No transaction costs}

Figure 5.5 shows the average life-cycle profiles of financial assets and total net worth and housing consumption. The evolution of wealth portfolio over the life cycle is similar to the one in the benchmark case.

In figure 5.6, we see the hump shape of average nonhousing consumption, with peak around age 50, which is similar to the one reported in the data and in the benchmark model. Nonhousing consumption decreases steadily with age after its peak.

Compared with the benchmark case, the decrease of stock of housings is too fast, and the ratio of housing consumption and non-housing consumption is almost constant after age 60. This contradicts to the empirical findings reported in section 2 .

These results show that the existence of transaction costs play an important role in explaining the slow downsizing of the housing consumption 
later in life.

\section{Sensitivity Analysis}

In this subsection we will check the robustness of the results to changes in parameters. First I change parameters that govern the bequest motives. Then I see the effect of down payment ratio. Also I change the elasticity of substitution between housing and non-housing. Finally I see the effect of introducing a pay-as-you-go social security system.

\subsection{Bequest motives}

First I present the results from a model without a voluntary bequest motive by setting $\phi_{1}=0$. Other parameters are adjusted accordingly to match the aggregate variable in the data. Figures 5.7 and 5.8 show the average lifecycle profiles of financial assets and total net worth, non-housing consumption and housing consumption. For the average household, the evolution of wealth portfolio over the life cycle is similar to the profiles in the benchmark case before retirement ${ }^{5}$. But After retirement, the drop of net worth and non-housing assets is more dramatically, compared with the profiles in the benchmark case. This finding is consistent with the ones in De Nardi (2003), that find that when bequest motive is modeled as luxury goods, the voluntary bequest motive kicks in for the richest $15-20 \%$ of the households, therefore has some effect on the average household profiles.

Figure 5.8 compares the average nonhousing and housing consumption in the case of no bequest motives and in the benchmark case. Compared with the benchmark case, consumption of non-housing goods is lower for the young agents but is higher for the old agents. In the benchmark case when households have voluntary bequest motives, more inheritance relax borrowing constraints for agents age 35-50, therefore consumption of non-housing is higher for young agents. Old agents with voluntary bequest motives would like to leave some resource to their offsprings therefore they would like to consume less themselves. The average elderly downsize their housings a little faster without bequest motive but the effect is small. The bequest motive, therefore, is not the key factor explaining the slow downsizing of housing stock later in life for the average household. The intuition here is that the

\footnotetext{
${ }^{5}$ The net worth and finacial assets level is higher for household aged 30-45 in the case without bequest motive. This comes from the generate equilibrium effect as the aggregate capital-output ratio is matched with the data.
} 
household faces transaction costs to downsize its stock of housings, but can borrow against it (at the same rate of return as saving). Since the average household plans to leave little bequests, it chooses to run down its net worth completely by the time it expects to be dead for sure, and it is here optimal to do so by borrowing against the stock of houses, rather than by selling the large house they live in, and buying a smaller one, and thus paying large transaction costs in the process.

Since the bequest-output ratio reported in Gale and Scholz (1994) is a low estimate of the magnitude of the bequest motive, I present the results from a model with a stronger voluntary bequest motive by match a bequestoutput ratio of 0.05 , witch corresponds to a bequest-GDP ratio of 0.0445 . Figures 5.9 and 5.10 show the average life-cycle profiles of financial assets and total net worth, non-housing consumption and housing consumption. After retirement, the profile of net worth and non-housing assets is moderate, compared with the profiles in the benchmark case. However, compared with the data, the decumulation of wealth is still too pronounced.

\subsection{Down Payment}

Now I check the effect of down payment on consumption paths and wealth paths. Down payment ratio does affect the consumption of housing and non-housing when household are young. When down payment ratio is high, young households has to wait longer to accumulate more financial assets to pay higher down payment to buy big houses. Since consumptions of housing and non-housing are non-separable, they could consume more nonhousing service instead. Figure 5.11 and figure 5.12 show the average lifecycle profiles of assets and consumption paths when the down payment ratio is 0.4. Compared with benchmark, the consumption of non-housing goods is higher and consumption of housing goods is lower at young age. Higher down payment ratio implies a tighter borrowing constraint, therefore young households could not borrow as much as in the benchmark economy and has a higher financial assets and higher net worth is in this case. Profiles of wealth and consumption are similar to these in the benchmark economy for middle and old households.

On the contrary, if down payment ratio is low, then young households are more likely to move into big house, therefore the housing profile increases quickly. Since utility from housing and non-housing is not separable, households compromise more non-housing consumption in the young age. Figure 5.13 and figure 5.14 show the average life-cycle profiles of assets and consumption paths when the down payment ratio is 0 . Compared with 
benchmark, the consumption of non-housing goods is lower and consumption of non-housing goods is higher at young age. Households use housing as a collateral and they have negative financial wealth until their forties, a point at which they begin to save for retirement. Profiles of wealth and consumption are similar to these in the benchmark economy for middle and old households.

\subsection{Elasticity of Substitution Between Housing and Non- housing Goods}

In this subsection we will check the robustness of the results to changes in elasticity of substitution between housing and non-housing. In the case of real business cycles models with household production (see Greenwood et al. (1995)), this elasticity governs the margin of substitution between the two sectors in the economy and is crucial. In my model without endogenous labor choice quantitatively it is of minor importance. Figure 5.15 and figure 5.16 compare the average life-cycle profiles of assets and consumption paths when the elasticity of substitution between housing and non-housing is 2 $(\sigma=0.5)$ with benchmark case. For the average household, the evolution of net worth and financial assets over the life cycle is similar to the profiles in the benchmark case. So is the non-housing consumption. However, housing stock is lower in the middle age and higher in the later age than in the benchmark.

Figure 5.17 and figure 5.18 compare the average life-cycle profiles of assets and consumption paths when the elasticity of substitution between housing and non-housing is $\frac{2}{3}(\sigma=-0.5)$ with benchmark case. For the average household, the evolution of net worth and financial assets over the life cycle is similar to the profiles in the benchmark case. So is the nonhousing consumption. However, housing stock is lower in the middle and later age than in the benchmark.

\subsection{Pay-as-you-go Social Security System}

I assume government plays no active role in the benchmark model. Now I compare a economy with pay-as-you-go social security system. I set the replacement rate to be $40 \%$, commonly used in the social security literature. I set social security tax to be $8 \%$ to balance the government budget. If I introduce Pay-as-you-go system in which the government taxes working agent and provide retired agent social security, then young agents are more likely

to be borrowing constrained therefore the average non-housing consumption 
increases slowly in the early life. Also adding pension system could decrease the hump of wealth profile. Figure 19 shows the average life-cycle profiles of assets when there is a pay-as-you-go social security system. Introducing a social security system discourage private saving thus the wealth at 65 , the year before retirement is much lower than in the benchmark case. Figure 20 shows the average life-cycle profiles of consumption paths. We observe the non-housing consumption reaches its hump at age 55,5 years later than in the benchmark case. This is cause by the even tighter borrowing constraint with social security tax. The decline of non-housing consumption is slower. This is caused by the general equilibrium effect. a Model with social security would discourage households to save for retirement, therefore a higher $\beta$ is needed to provide a strong saving motive to match the capital-output ratio. Agents build up their highest housing stock at the age of 60,5 years later than the peak of non-housing consumption. Elderly do not down size their stock of housing later in life.

I present the results from a model with a stronger voluntary bequest motive by match a bequest-output ratio of 0.05 , witch corresponds to a bequest-GDP ratio of 0.0445 . Figures 5.21 and 5.22 show the average lifecycle profiles of financial assets and total net worth, non-housing consumption and housing consumption. After retirement, the profile of net worth and non-housing assets is moderate, compared with the profiles in the benchmark case. However, compared with the data, the decumulation of wealth is still too pronounced. This can be explained by the absence of health uncertainty or other shocks that could motivate precautionary assets holding in old age. Old agents do not have a precautionary saving motives as they do in the data therefore they run down their assets more quickly that in the data.

\section{Conclusions}

This paper investigates the degree to which several modification of the basic life-cycle model produce consumption profiles of housing and non-housing that more closely resemble features of the U.S. To do this, I develop a quantitative and realistically calibrated model to solve numerically for the optimal housing and nonhousing consumption decision for a finitely-lived individual who faces several market frictions.

The model is able to match two basic patterns observed in the data: the hump shaped non-housing consumption profile and non-hump shaped housing consumption profile. Households begin their economic lives without 
any stock of housings. During the early part of their lives, they are forced to build stock of housing and compromise on the non-housing consumption. As households age, they start to decrease their nonhousing consumption due to the fact that time preference is higher than the interest rate and mortality rates are increasing along the life cycle. The high transaction costs associated with trading housing good prevent household from decumulating their housing stock quickly later in life.

The model is also able to capture the life cycle wealth portfolio profiles. According to Fernandez-Villaverde and Krueger (2001), in the U.S., young households virtually own no liquid financial assets, but hold a major fraction of their wealth as housings. Later in life, households shift their portfolios to financial assets.

I also investigate the quantitative relevance of the transaction costs, borrowing constraints and bequest motives in determining this patterns. I find that while borrowing constraints are essential at explaining the accumulating of housing assets in the early life, the existence of transaction costs is crucial to explain the slow downsizing of housing profile in the later life. The bequests motive plays a role in determining total life time wealth, but not its life cycle evolution.

In this paper I have abstracted from some important issues in order to make the model manageable and solvable. Now I discuss these simplifications and their likely quantitative implications.

One important assumption is that there are no intervivos transfers. In the data, parents tend to give children money when they need money the most, although data from Health and Retirement Study suggests that these transfer are fairly small (see Cardia and $\mathrm{Ng}$ (2000)). This assumption is probably relevant when agents are 20 to 35 years of age. Allowing for intervivos transfer would make children have higher consumption of housing and non-housing when they are young.

In order to simplify the computation, I do not adopt the literature using endogenous borrowing constraints. Fernandez-Villaverde and Krueger (2001) compare the life cycle profiles in a model with endogenous borrowing constraints with the exogenous constraints as in this model and they show that the life cycle profiles are identical across this two economies. The major difference between the two economies is that with endogenous borrowing constraints the net worth of the average young agents is slightly negative, indicating young agents are borrowing to fiance the accumulation of housings and to smooth consumption over time and states. Since I focus on the consumption patterns later in life, I abstract from the endogeneity of borrowing constraints. 
Another important assumption that I make is that there is no housing rental market. In the Survey of Income and Program Participation (SIPP), housing ownership for two-person households is lower for young households and then increase to $75 \%$ at the age of 30, staying flat and declining only slightly after age 75 (Venti and Wise (2001)). They find that in the absence of a shock, death of a spouse or entry of a family member into a nursing home,-families are unlikely to discontinue home ownership. And even when there is a precipitating shock, discontinuing ownership is the exception rather than the rule. Thus the lack of rental market is probably relevant for young households but less relevant for middle and old age households. I could incorporate a rental market into the framework to see if the results presented in this paper are robust to the existence of rental market.

I assume that there is no cost of borrowing using housing as collateral. The fixed closing costs associated with refinancing a mortgage or applying for a second mortgage are estimated at 1.5 to 2.5 percent of the household's initial mortgage balance, although accessing home equity has become much easier in the 1990's relative to 1980's (Bennett, Peach and Peristiani (1998)). Hurst and Stafford (2004) explore the use of equity as a mechanism by which households smooth their consumption over time and find that households with low income realizations are much more likely to refinance than households with medium or high income draws. Their analysis assumes households have fixed housing stock and focuses on the impact of temporary income shocks on refinancing decisions. It will be interesting to extend my model to look at the effect of income shock on households moving decisions and refinancing decision jointly.

I assume that elderly do no face any health shocks. Even in presence of social insurance (Medicare and Medicaid), households can face substantial out-of-pocket medical expenses (see French and Jones (2003), Palumbo (1999) and Feenberg and Skinner (1994)). Moreover nursing home expenses are potentially large and virtually uninsurable (Cohen, Tell and Wallack (1986)). The risk of incurring such medical expenses might generate precautionary savings. The effect of medical costs on the life cycle consumption and saving in an environment with housing is left for future research. 


\section{References}

[1] Aiyagari, R. (1994): "Uninsured Idiosyncratic Risk and Aggregate Saving," The Quarterly Journal of Economics, 109, 659-684.

[2] Atkinson, A., Rainwater, L. and T.M. Smeeding (1995), "Income Distribution in OECD Countries: Evidence from the Luxembourg Income Study (LIS)". Social Policy Studies 18, OECD.

[3] Altonji, J. G., and E. Villanueva (2002): "The Effect of Parental Income on Wealth and Bequests," Working paper, Northwestern University.

[4] Attanasio, O.P., "Consumption", chapter 11, Handbook of Macroeconomics, North Holland, Elsevier.

[5] (1995): "The Intertemporal Allocation of Consumption: Theory and Evidence", Carnegie-Rochestor Conference Series on Public Policy 42, 39-89.

[6] Attanasio, O.P., J. Banks, C. Meghir and G. Weber (1999), "Humps and Bumps in Lifetime Consumption". Journal of Business and Economics, 17, 22-35.

[7] Attanasio, O., P.K. Goldberg and E. Kyriazidou (2000), "Credit Constraints in the Market for Consumer durables; Evidence from Microdata on Car Loans," NBER Working Paper 7694.

[8] Attanasio, O. and G. Weber (1995): "Is Consumption Growth Consistent with Intertemporal Optimization? Evidence for the Consumer Expenditure Survey," Journal of Political Economy 103, 1121-1157.

[9] Bell, F. C., A. H. Wade, and S. C. Goss (1992): "Life Tables for the United States Social Security Area: 1900-2080," Social Security Administration, Office of the Actuary.

[10] Bennett, Paul, R. Peach and S. Peristiani (1998): "Structural Change in the Mortgage Market and the Propensity to Refinance", Journal of Money, Credit and Banking, 2001, vol. 33, issue 4, pages 955-75.

[11] Blundell, R., M. Browning and C. Meghir (1994), "Consumer Demand and the Life-Cycle Allocation of Household Expenditures". Review of Economic Studies 61, 57-80. 
[12] Browning, M. (1992): "Children and Household Economics Behavior", Journal of Economic Literature 30, 1434-1475.

[13] Buhmann, B., Rainwater, L., Schmauss G. and T.M. Smeeding (1988), "Equivalence Scales, Well-Being, Inequality and Poverty: Sensitivity Estimates across Ten Countries Using the Luxembourg Income Study Database". Review of Income and Wealth, 34, 115-142.

[14] Caplin, Andrew, Sewin Chan, Charles Freeman, and Joseph Tracy (1997): Housing partnerships: A new approach to markets at a crossroads. Cambridge: MIT Press.

[15] Cardia, E. and S. Ng (2000): "How Important are Intergenerational Transfers of Time? A Macroeconomic Analysis," Working paper, Johns Hopkins University.

[16] Carroll, C. D. (2001): "A Theory of Consumption Function, With or Without Liquidity Constraints," Journal of Economic Perspectives, 15.

[17] Chah, E., V. Ramey and R. Starr (1995): "Liquidity Constraints and Intertemporal Consumer Optimization: Theory and Evidence from housing," Journal of Money, Credit and Banking 27, 272-287.

[18] Chinloy, P. (1980): "An Emperical Model of the Market of Resale Homes", Journal of Urban Economics, May, 279-292.

[19] Marc A. Cohen, Eileen J. Tell, and Stanley S. Wallack. The lifetime risks and costs of nursing home use among the elderly. Medical Care, 24:1161-1172, 1986.

[20] Cooley, T. F. and E. C. Prescott (1995): Economic growth and business cycles. In T. F. Cooley (Ed.), Frontiers of Business Cycle Research, Chapter 1. Princeton: Princeton University Press.

[21] Diaz, A. and M. J. Luengo-Prado (2003): "Precautionary Saving and Wealth Distribution with housing," Working paper.

[22] Diaz-Gimenez, J., E. Prescott, T. Futzgerald, F. Alvarez(1992). "Banking in Computable General Equilibrium Economics", Journal of Economic Dynamics and Control, 16 533-559

[23] Diaz-Gimenez, J. and L. A. Puch (1998): "Borrowing constraints in economies with indivisible household capital and banking: an application to the spanish housing market (1982-89)". Investigaciones Economicas 22 (3), 469-499. 
[24] De Nardi, M. (2004): "Wealth Inequity and Intergeneration links", Review of Economic Studies, 71, 734-768.

[25] Eberly, J. (1994): "Adjustment of Consumers housings Stocks: Evidence from Automobile Purchases" Journal of Political Economy, 102, 403-436.

[26] Engelhardt, G. (1996): "House Prices and Home Owner Saving Behavior," Regional Science and Urban Economics, 26, 313-336.

[27] Daniel Feenberg and Jonathan Skinner. The risk and duration of catastrophic health care expenditures. Review of Economics and Statistics, 76:633-647, 1994.

[28] Fernandez-Villaverde, J., and D. Krueger (2001): "Consumption and Saving over the Life Cycle: How Important are Consumer durables?" Proceedings of the 2002 North American Summer Meetings of the Econometric Society.

[29] - (2002): "Consumption over the Life Cycle: Some Facts from Consumer Expenditure Survey Data ," Working paper.

[30] Flavin, M. and T. Yamashita (2000): "Owner-Occupied Housing and the Composition of the Household Portfolio," NBER Working Paper 6389 .

[31] Eric French and John Bailey Jones. On the distribution and dynamics of health care costs. Journal of Applied Econometrics, 2004. forthcoming.

[32] Gale, W., and J. K. Scholz (1994): "Intergenerational Transfers and the Accumulation of Wealth," Journal of Economic Perspectives, Autumn, 1994, 145-160.

[33] Gourinchas, P. O., and J. A. Parker (2002): "Consumption over the Life Cycle," Econometrica, 70(1): 4789.

[34] Grossman, S. and G. Laroque (1990): "Asset Pricing and Optimal Portfolio Choice in the Presence of Illiquid housing Consumption Goods," Econometrica, 58, 25-51.

[35] Gruber, J and R. Martin(2003). "Does Housing Wealth Make Us Less Equal? The Role of housing in the Distribution of Wealth," working paper. 
[36] Hansen, G. D. (1993): "The Cyclical and Secular Behavior of the Labor Input: Comparing Efficiency Units and Hours Worked," Journal of Applied Econometrics, 8, 71-80.

[37] Hurst, E, F. Stafford (2003): "Home is Where the Equity is: Mortgage Refinancing and Household Consumption", Working Paper.

[38] Johnson, D.S. and T.I. Garner (1995), "Unique Equivalence Scales: Estimation and Implications for Distributional Analysis", Journal of Income Distribution 4, 215-234.

[39] Laitner, J. (2001): "Wealth Accumulation in the U.S.: Do Inheritance and Bequests Play a significant Role?" Working paper.

[40] Leigh, W.A. (1980): "Economic Depreciation of the Residential Housing Stock of the United States, 1950-1970," Review of Economics and Statistics, 62, 200-206.

[41] Lustig, H.., and S. Van Nieuwerburgh (2002). "Housing Collateral, Consumption Insurance and Risk Premia," Working paper, University of Chicago.

[42] Martin, R. F. (2003): "Consumption, housing and Transaction costs," International Finance Discussion Paper No 756. Board of Governors Federal Reserve System.

[43] Merril, S. R. (1984): "Home Equity and the Elderly", in Retirement and Economics Behavior, ed. Henry J. Aaron and Gary Burtless. Washington, DC: Brookings Institution.

[44] Ogaki, M. and C.M. Reinhart (1998): "Measuring Intertemporal Substitution: The Role of housing". Journal of Political Economy 106, 1078-1098.

[45] Michael G. Palumbo. Uncertain medical expenses and precautionary saving near the end of the life cycle. Review of Economic Studies, 66:395-421, 1999 .

[46] Sheiner, L., and D. Weil (1992): "The Housing Wealth of the Aged", NBER working paper 4115.

[47] Smith, K. B., K. T. Rosen, and G. Fallis (1988): "Recent Developments in Economic Models of Housing Markets," Journal of Economic Literature, Vol. XXVI, 29-64. 
[48] Tauchen, G. and R. Hussey (1991): "Quadrature-Based Methods for Obtaining Approximate Solutions to Nonlinear Asset Pricing Models," Econometrica, 59, 371-396.

[49] Venti, S. F., and D. A. Wise (1990): "But they don't want to Reduce Housing Equity," In Issues in the Economic of Aging, ed. David A. Wise. Chicago: University of Chicago Press.

[50] Venti, S. F., and D. A. Wise (1991): "Aging and the Income Values of Housing Wealth," Journal of Public Economics, 44:371-97.

[51] Venti, S. F., and D. A. Wise (2001): "Aging and Housing Equity: Another Look", Working paper.

[52] Yang, F. (2004): "How Do Households Portfolio Vary with Age?", Working paper.

[53] Zeldes, S. (1989), "Consumption and Liquidity Constraints: An Empirical Investigation". Journal of Political Economy 97, 305-346.

[54] Zimmerman, D. J. (1992): "Regression Toward Mediocrity in Economic Stature," American Economic Review, 82(3), 409-429. 


\section{$.1 \quad$ Calibration}

I calibrate my model following Cooley and Prescott (1995) and Diaz and Luengo-Prado (2002). I use data from the National Income and Product Accounts and the Fixed Assets Tables published by the Bureau of Economic Analysis for the year 1959-1999. In order to properly calibrate a model with two assets and without government taxes and expenditures, I make some imputations.

Define measured GDP as the sum of each final expenditures:

$$
G D P=\left(c+s h+i_{c d}+c_{g}\right)+\left(i_{p r k}+i_{p n r k}+i_{g}\right)+n x+\triangle i n v
$$

where $c, s h, i_{c d}, c_{g}$ are expenditures on nonhousing and service excluding housing, housing services, expenditures on consumer durables, government consumption expenditures. Thus $\left(c+s h+i_{c d}+c_{g}\right)$ are consumption expenditure. $i_{\text {prk }}, i_{\text {pnrk }}, i_{g}$ are total private residential investment, nonresidential investment and government investment. Thus $i_{p r k}+i_{p n r k}+i_{g}$ are total investment.

I also write GDP as the sum of wages plus rents of residential and nonresidential stocks of capital:

$$
G D P=w e+p r k \cdot r_{p r k}+p n r k \cdot r_{p n r k}
$$

To explicitly consider the existence of residential housings I rearrange output as

$$
G D P=\left(c+i_{c d}+c_{g}\right)+s h+i_{p r k}+\left(i_{p n r k}+i_{g}+n x+\triangle i n v\right)
$$

Since there is no rental market in this model, I subtract rental income from residential housing from GDP.

$$
\begin{aligned}
Y & =w e+p n r k \cdot r_{p n r k}=G D P-s h \\
K & =p n r k+i n v+g \\
D & =p r k \\
i_{d} & =i_{p r k}
\end{aligned}
$$

$K$ includes private fixed non-residential assets and government fixed nonresidential assets. $D$ includes private fixed residential assets and government 
fixed residential assets. Both measures are taken from the Fixed Assets Tables.

Following Cooley and Prescott (1995), I define unambiguous capital income (UCI) as rental income, corporate profits and net interest, and define ambiguous capital income (ACI) as other income exclude wage and depreciation. Thus capital income $Y_{k}$ is defined as UCI $+\alpha \cdot \mathrm{ACI}+$ depreciation$\operatorname{sh}=\alpha \cdot Y$

Subtracting housing from output, the share of capital is calibrated as,

$$
\alpha=(U C I+d e p-s h) /(Y-A C I)
$$

I computer an average share of capital $\alpha=0.2261$, an average capital-

output ratio $\frac{K}{Y}=1.9887$, an Investment-capital ratio $\frac{i_{k}}{K}=0.0700$, a housing stock to output ratio, $\frac{D}{Y}=1.2141$, an investment-housing stock ratio, $\frac{i_{d}}{D}=$ 0.0294 and a nonhousing to housing investment ratio, $\frac{C}{i_{d}}=15.9443$. The implied interest rate net of depreciation in a steady state is $r=\alpha \frac{Y}{K}-\frac{i_{k}}{K}=$ $3.17 \%$.

\section{.2 Computation of the Model}

Since I introduce the non-convex transaction costs on housing, I could not use Euler equation approximation or policy function iteration. Hence I solve the model using approximation of value function.

To compute the steady state of our model, I first discretize income process and income inheritance process following Tauchen and Hussey(1991). The state space for housing and asset holdings are discretized. Choices are not restricted to be in the grid. For choices between grid points, linear interpolation is used. The upper bounds on the grids are chosen large enough so that they do not constitute a constraint on the optimization problem. Using this grid I can store the value functions and the distribution of households as finite-dimensional arrays.

I solve the approximated optimal consumption and saving plans recursively. Households surviving to the last period $T$ has a easy problem to solve. Based on the period $T$ policy functions, I solve the consumption and saving decisions that maximaze the period $T-1$ value function. The same procedure is carried back untile decision rules in the first period are computed for a large number of states.

I solve for the steady state equilibrium as follows:

1. Given an initial guess of interest rate $r$, use the equilibrium conditions in the factor markets to obtain the wage rate $w$. 
2. Guess an initial bequest distribution.

3. Set the interval for housings and assets.

4. Set value function after the last period to be 0 , I solve the value function for the last period of life for each of the points of the grid. This yields policy functions and value function at the last period.

5. By backward induction, repeat the steps 4 until the first period in life.

6. Compute the associated stationary distribution of households by forward induction using the policy functions starting from the known distribution over types of age.

7. Check if the distributions of housings and assets do not have a large mass at the maximum levels. If so, increase the maximum level and go back to step 3. If not, continue to step 8.

8. Given the stationary distribution and policy functions, compute the bequest distribution. If the bequest distributions converges, go to step 9; otherwise go to step 2.

9. Given the stationary distribution and prices, compute factor input demands and supplies and check market clearing conditions hold.

10. If all markets clear, an equilibrium is found. If not, go to step 1 and update interest rate $r$.

\section{$.3 \quad$ Transition function}

From the policy rules, the bequest distribution, and the exogenous Markov process for productivity, we can derive a transition function $\widetilde{M}(x ; \cdot)$, which is the probability distribution of $x^{\prime}$ (the state in the next period), conditional on $x$, for a person who behaves according to the policy rules $c(x), a^{\prime}(x)$ and $h^{\prime}(x)$. The measurable space over which $\widetilde{M}$ is defined is $(\widetilde{X}, \mathfrak{B}(\widetilde{X}))$, with

$$
\begin{aligned}
X & =\{1, \ldots, T\} \times \mathbb{R}_{+} \times \mathbb{R}_{+} \times Y \times(Y \cup\{0\}) \\
\mathfrak{B}(X) & =\mathcal{P}(\{1, \ldots, T\}) \times \mathfrak{B}\left(\mathbb{R}_{+}\right) \times \mathfrak{B}\left(\mathbb{R}_{+}\right) \times \mathfrak{B}(Y) \times \mathfrak{B}(Y \cup\{0\}) \\
\widetilde{X} & =X \cup D \\
\mathfrak{B}(\widetilde{X}) & =\{x: x=X \cup d, X \in \mathfrak{B}(\tilde{X}), d \in(\phi, D)\}),
\end{aligned}
$$

where $\mathcal{P}$ is the cardinal set of $\{1, \ldots, T\}$ and $D$ indicates that a person is dead.

To characterize $\widetilde{M}$, it is enough to display it for the sets

$L(\bar{t}, \bar{a}, \bar{h}, \bar{y}, \overline{y p})=\left\{\left(t^{\prime}, a^{\prime}, h^{\prime}, y^{\prime}, y p^{\prime}\right) \in X: t^{\prime} \leq \bar{t}, a^{\prime} \leq \bar{a}, h^{\prime} \leq \bar{h}, y^{\prime} \leq \bar{y}\right.$, $\left.y p^{\prime} \leq \overline{y p}\right\}$. 
On such sets $\widetilde{M}$ is defined by

$$
\begin{array}{rlrl}
\widetilde{M}(x, L(\bar{t}, \bar{a}, \bar{h}, \bar{y}, \overline{y p})) & =s_{t} I_{t+1 \leq \bar{t}}\left\{I_{a^{\prime}(x) \leq \bar{a}}\left(I_{y p=0}+I_{y p \leq \overline{y p}} s_{t+6}\right)+\right. \\
\mu_{b}(x) & \left.:\left[0, \bar{a}-a^{\prime}(x)\right]\left(1-s_{t+6}\right) I_{y p>0}\right\} I_{h^{\prime}(x) \leq \bar{h}} Q_{y}(y,[0, \bar{y}] \cap Y) \text { if } \mathrm{x}(21) \\
& =0 & \text { if } \quad x=213)
\end{array}
$$

where $I$ is an indicator function, which equals one if the subscript property is true and zero otherwise.

In the above equation, $s_{t}$ is the probability of surviving into the next period. the presence of $I_{t+1<\bar{t}}$ shows that conditional on survival, a person currently of age $t$ will be of age $t+1$ next period. If the person's parent is already dead, that is, $y p=0$, the person cannot receive bequests anymore, and his or her assets next period are $a^{\prime}(x)$ for sure. (As discussed above, this is always the relevant case for people 50 and older.) If, instead, the parent is still alive, that is, $y p>0$, the parent can survive into the next period with probability $s_{t+6}$. In that case, tomorrow's assets for the person will be $a^{\prime}(x)$ and $y p^{\prime}=y p$. Alternatively, the parent may die, with probability $1-s_{t+6}$. In this case, the person inherits next period, $y p^{\prime}=0$, and the probability that next period's assets are no more than $\bar{a}$ is the probability of receiving a bequest between 0 and $\bar{a}-a^{\prime}(x)$. The person's evolution of productivity is described by $Q y$. Note that the evolution of productivity, a person's survival, and the survival of the person's parent are independent of each other. The last line shows that death is an absorbing state.

In the economy as a whole, I am not interested in keeping track of dead people, so I will define a operator on measures on $(X, \mathfrak{B}(X))$. Furthermore, I must take into account that new people enter the economy in each period. The transition function is defined as

$M(x, L(\bar{t}, \bar{a}, \bar{h}, \bar{y}, \overline{y p}))=\frac{\widetilde{M}(x, L(\bar{t}, \bar{a}, \bar{h}, \bar{y}, \overline{y p}))+n^{7} I_{t=7} Q y(y,[0, y] \cap Y) I_{y=y p^{\prime}}}{n}$

The transition function $M$ differs from $\widetilde{M}$ in two ways. First, it accounts for population growth; when population grows at rate $n$, a group that is $1 \%$ of the population becomes $1 / n \%$ in the subsequent period. Second, it accounts for births, which explains the second term in the numerator. If a person is 50 years old $(\mathrm{t}=7)$, that person's children (there are $n^{7}$ of them) will enter the economy next period. All of those children have age $t=1$ and zero assets and zero housing. Their stochastic productivity is inherited 
from their 50-year-old parent, according to the transition function $Q y h$. $y$ is their parent's productivity at 50 .

The operator $R_{M}$ is thus defined as following to map measures on ( $X$, $\mathfrak{B}(X))$ into measures on $(X, \mathfrak{B}(X))^{6}$ :

$$
\left(R_{M} m\right)(\chi)=\int M(x, \chi) m(d x), \quad \forall \chi \in \mathfrak{B}(X) .
$$

\section{.4 Consistency of bequest distribution}

I want to calculate the distribution $l(\cdot \mid t, y)$ of parents at age $50-80$, conditional on the parent's productivity at age 50 and conditional on being alive. First I define $m^{*}(\cdot \mid t, y)$ as the conditional distribution of $x$ given age $t$ and productivity $y$. For any given $(t, y), m^{*}(\cdot \mid t, y)$ is a probability distribution on $(X, \mathfrak{B}(X))$. For any $\chi \in \mathfrak{B}(X), m^{*}(\cdot \mid t, y)$ is measurable with respect to $\mathcal{P}(\{1, \ldots, T\}) \times \mathfrak{B}(Y)$ and is such that

$\int_{\chi_{t, y}} m^{*}(\cdot \mid t, y) m_{t, y}^{*}(d t, d y)=m^{*}(\chi) \quad \forall \chi \in \mathfrak{B}(X) \quad \forall \chi_{t, y} \in \mathcal{P}(\{1, \ldots, T\}) \times \mathfrak{B}(Y)$.

The children observe the parent's productivity at age 50 . Therefore the conditional distribution of the parent at age 50 at productivity level $y_{p}$ is $m^{*}\left(\cdot \mid t=6, y=y_{p}\right)$. Therefore $l\left(\chi \mid t=6, y=y_{p}\right)=m^{*}\left(\chi \mid t=6, y=y_{p}\right)$

and recursively using the transition function $\widetilde{M}$ defined the section above, we define

$$
l\left(\chi \mid t+1, y_{p}\right)=\frac{\int_{X} \widetilde{M}(x, \chi) l\left(d x \mid t, y_{p}\right)}{s_{t}} .
$$

Since the bequest is evenly distributed among children, the probability distributions for bequests $\mu_{b}(x ;:)$ for a person with state $x=(t, a, h, y, y p)$ is given by

$$
\begin{array}{rll}
\mu_{b}(x & : & \left.\chi_{a, h}\right)=l\left(a \in \mathbb{R}_{+}, h \in \mathbb{R}_{+}:\left(n^{6} a, n^{6} h\right) \in \chi_{a, h} \mid t+6, y_{p}\right) \\
\forall \chi_{a, h} & \in & \mathfrak{B}\left(\mathbb{R}_{+}\right) \times \mathfrak{B}\left(\mathbb{R}_{+}\right), \forall a, h \in \mathfrak{B}\left(\mathbb{R}_{+}\right) \forall y, y p \in \mathfrak{B}(Y)
\end{array}
$$

\footnotetext{
${ }^{6}$ For detailed discuss of the property of operator $R_{M}$ in a similar environment, please refer to De Nardi (2004).
} 
Demographics

$n \quad$ population growth

$1.2 \%$

$p_{t} \quad$ Survival probability

see text

Preference

$\eta \quad$ risk aversion coefficient

1.5

$\sigma \quad$ substitutability of housings and non-housings

$a$ weights of non-housing in utility function

0.859

$\beta \quad$ discount factor

0.929

$\phi_{1} \quad$ weight of bequest in utility function

$-24$

$\phi_{2} \quad$ shifter of bequest in utility function

Technology

$\alpha \quad$ capital share in National Income

0.226

$\delta \quad$ depreciation rate of capital

0.0700

$\delta^{d} \quad$ depreciation rate of housing

0.0294

Endowment

$\rho_{y} \quad \operatorname{AR}(1)$ coefficient of income process $\quad 0.85$

$\varepsilon_{y}^{2} \quad$ innovation of income process 0.30

$\rho_{y h} \quad \mathrm{AR}(1)$ coefficient of income inheritance process $\quad 0.677$

$\varepsilon_{y h}^{2} \quad$ innovation of income inheritance process $\quad 0.37$

Housing market

$\theta \quad$ down payment ratio $\quad 0.20$

$\rho_{1} \quad$ transaction costs of selling housings $\quad 0.04$

$\rho_{2} \quad$ transaction costs of buying housings $\quad 0.04$

$\mu_{1}$ Maximum depreciation 0

$\mu_{2}$ Maximum renovation 0

Table 4.1: Parameters used in the benchmark model 


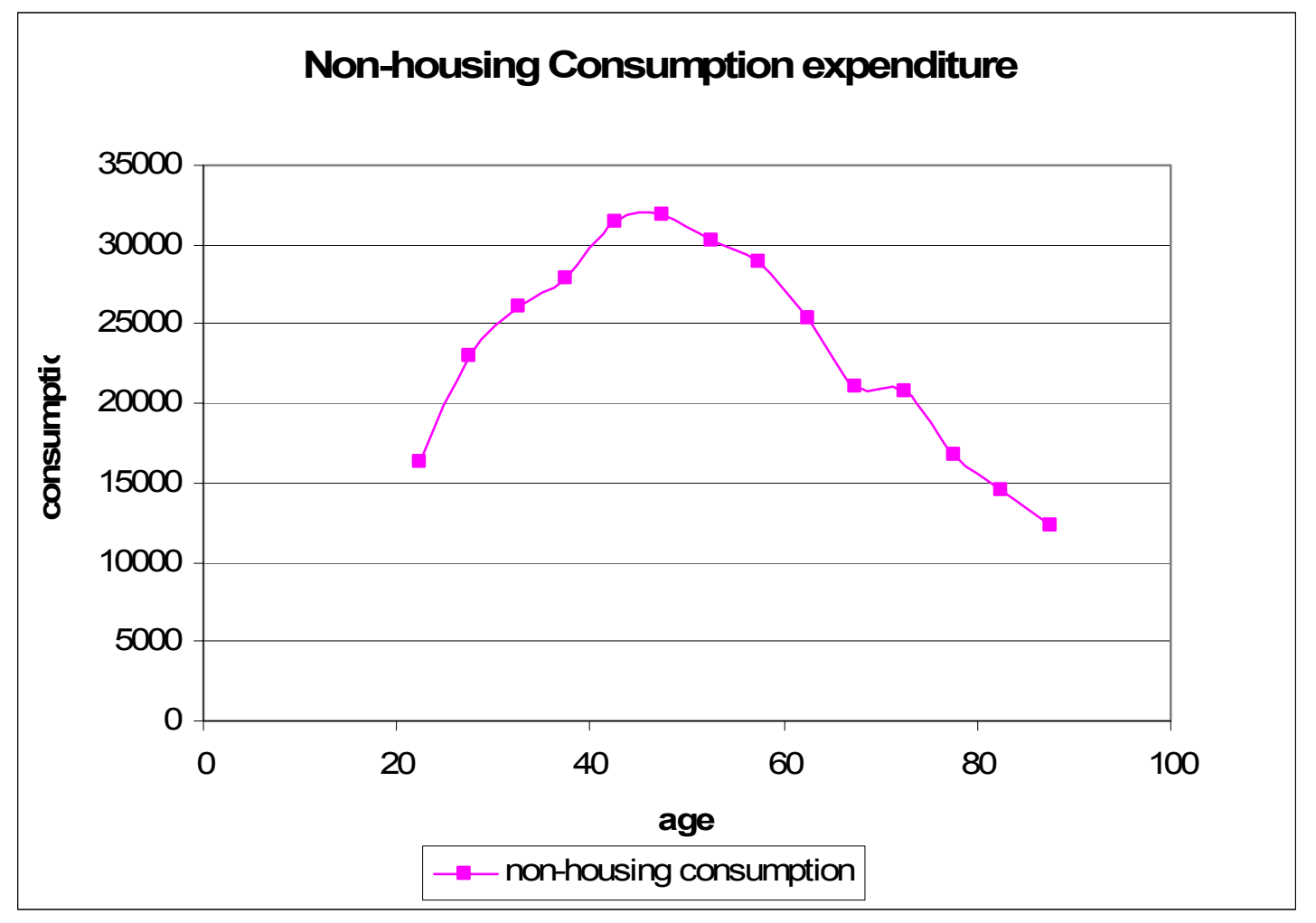

Figure 2.1: Non-housing Expenditure 


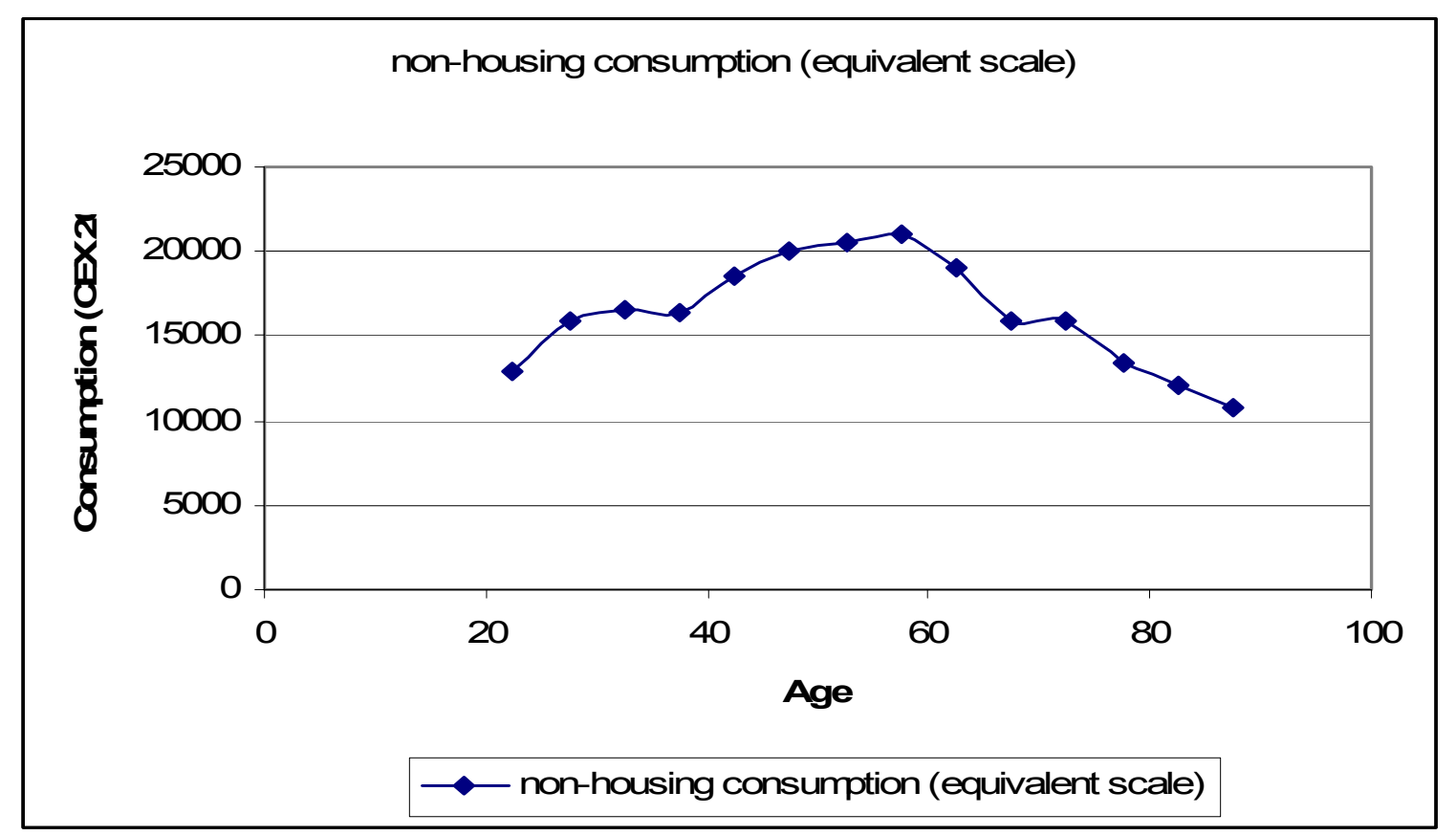

Figure 2.2: Non-housing Expenditure (adult equivalent) 


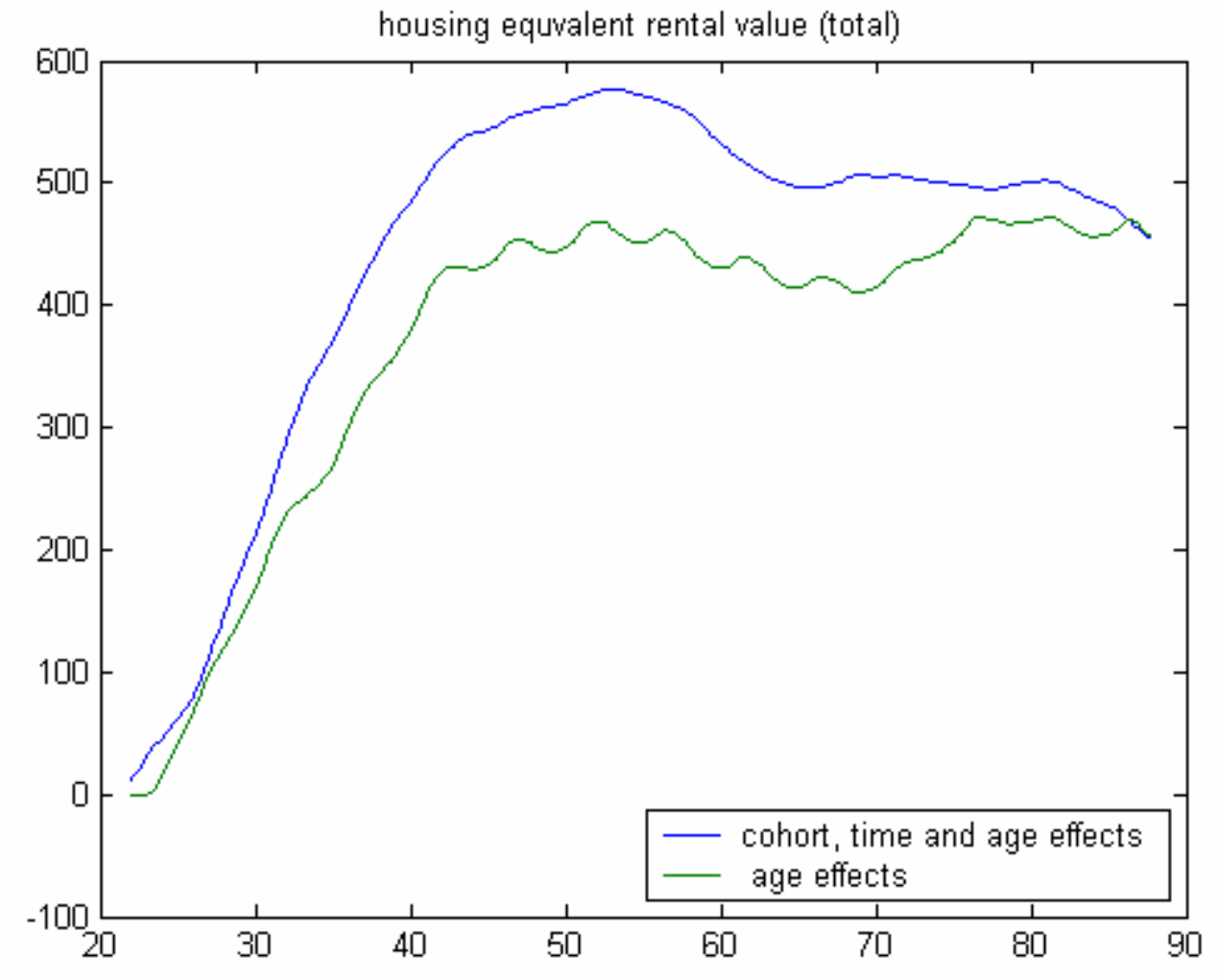

Figure 2.3: Equivalent rental value of housing 


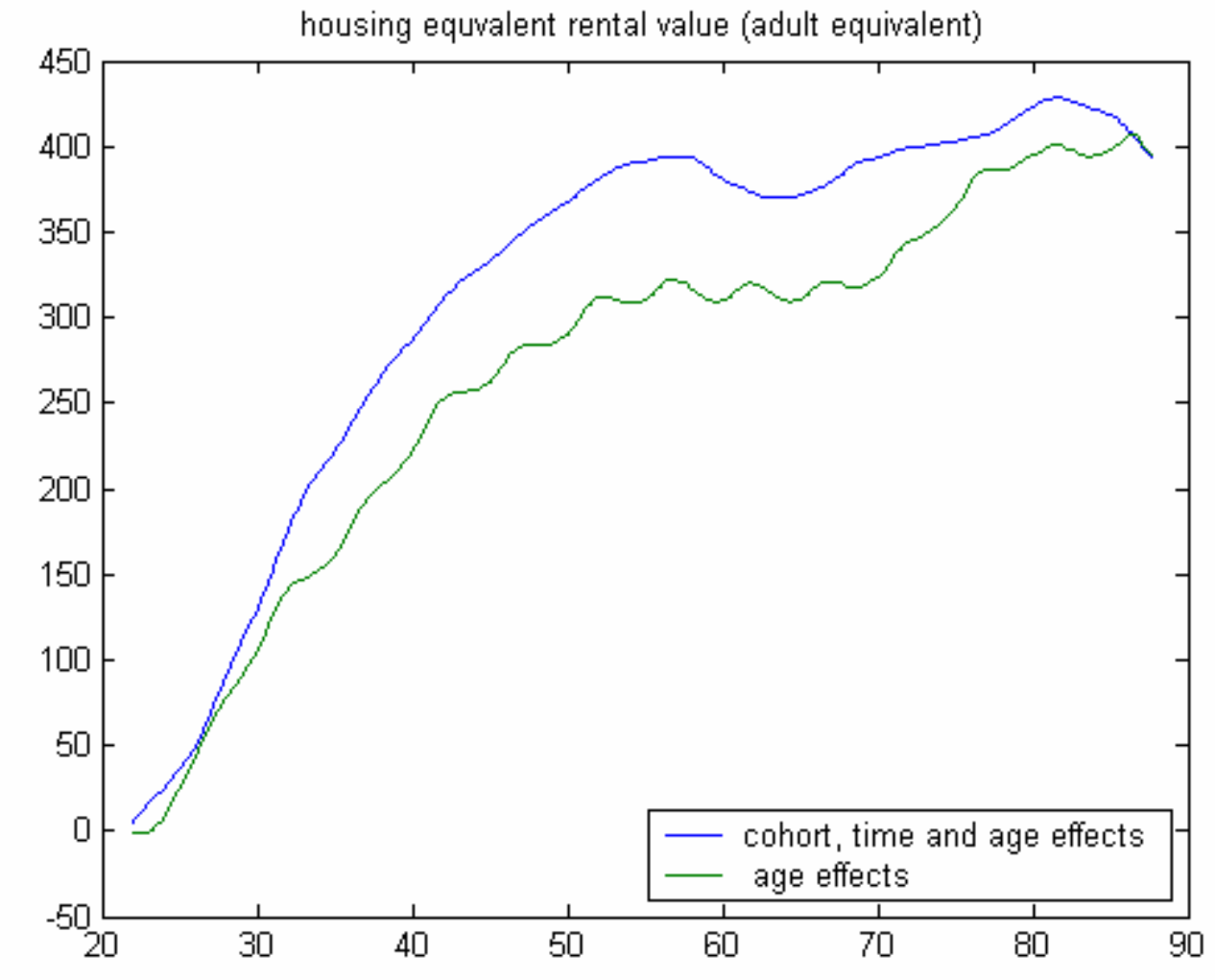

Figure 2.4: Equivalent rental value of housing (adult equivalent) 


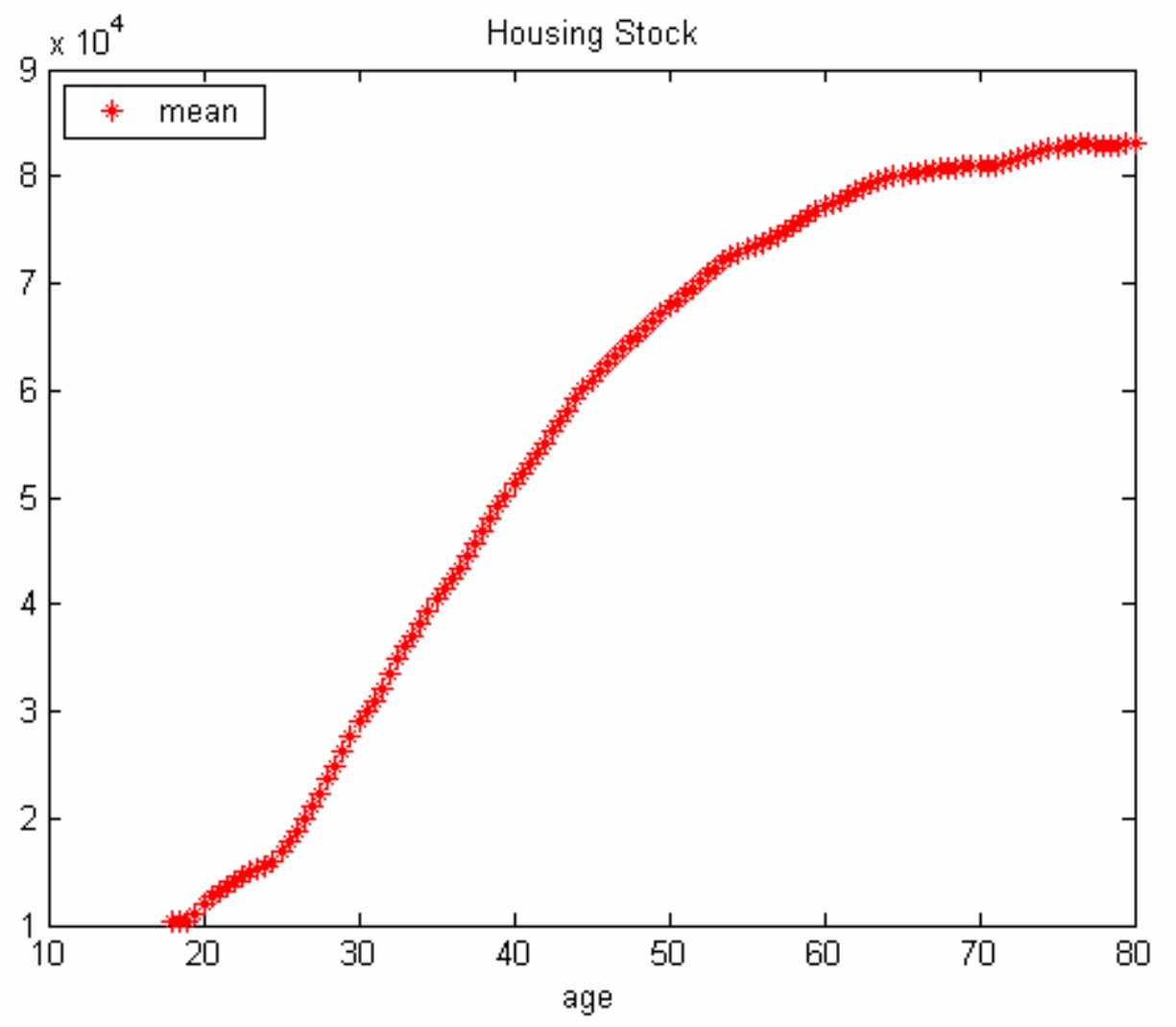

figure 2.5: Age profile of housing assets estimated from SCF

45 


\begin{tabular}{lrrrrrrrr|r} 
Generation t-6 & \multicolumn{1}{c|}{$\mid$} & & & & & \\
(Parents) & 50 & 55 & 60 & 65 & 70 & 75 & 80
\end{tabular}

\section{Generation $t$}

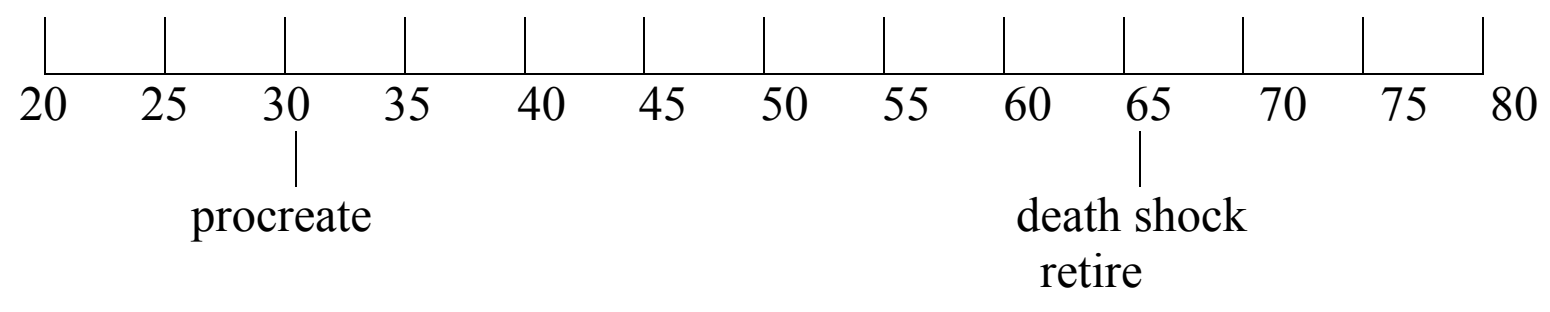

Generation $\mathrm{t}+6$

(Children)

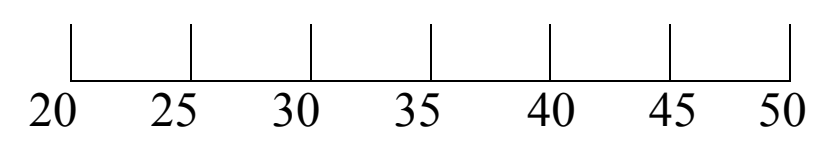

Table 3.1: demographics 


\begin{tabular}{|c|c|c|}
\hline & Data & Benchmark \\
\hline $\mathrm{k} / \mathrm{y}$ & 1.989 & 1.989 \\
\hline $\mathrm{d} / \mathrm{y}$ & 1.214 & 1.21 \\
\hline $\mathrm{c} / \mathrm{y}$ & 0.768 & 0.763 \\
\hline
\end{tabular}

Table 5.1 Aggregate Ratios

\begin{tabular}{|c|c|l|c|c|c|c|c|c|c|}
\hline & Gini & $1^{\text {st }}$ & $2^{\text {nd }}$ & $3^{\text {rd }}$ & $4^{\text {th }}$ & $5^{\text {th }}$ & $\begin{array}{c}\text { Top } \\
10 \%\end{array}$ & Top 5\% & Top 1\% \\
\hline Total wealth & & & & & & & & & \\
\hline U.S. data & 0.81 & -1.1 & 1.25 & 4.48 & 11.79 & 82.60 & 69.63 & 57.37 & 32.09 \\
\hline Model & 0.72 & 0.13 & 0.77 & 5.40 & 18.91 & 74.78 & 52.92 & 33.93 & 9.72 \\
\hline Housing & & & & & & & & & \\
\hline U.S. data & 0.64 & 0 & 1.52 & 12.24 & 22.56 & 63.69 & 45.10 & 31.21 & 12.68 \\
\hline Model & 0.49 & 1.7243 & 7.44 & 14.78 & 23.10 & 52.95 & 28.70 & 15.58 & 3.77 \\
\hline $\begin{array}{c}\text { Financial } \\
\text { wealth }\end{array}$ & & & & & & & & & \\
\hline U.S. data & 1.18 & -14.48 & -2.00 & 0.28 & 6.06 & 110.14 & 96.79 & 80.51 & 48.40 \\
\hline Model & 0.93 & -6.53 & -2.42 & 1.35 & 16.46 & 91.14 & 67.23 & 44.62 & 13.24 \\
\hline
\end{tabular}

Table 5.2 Wealth Distribution 


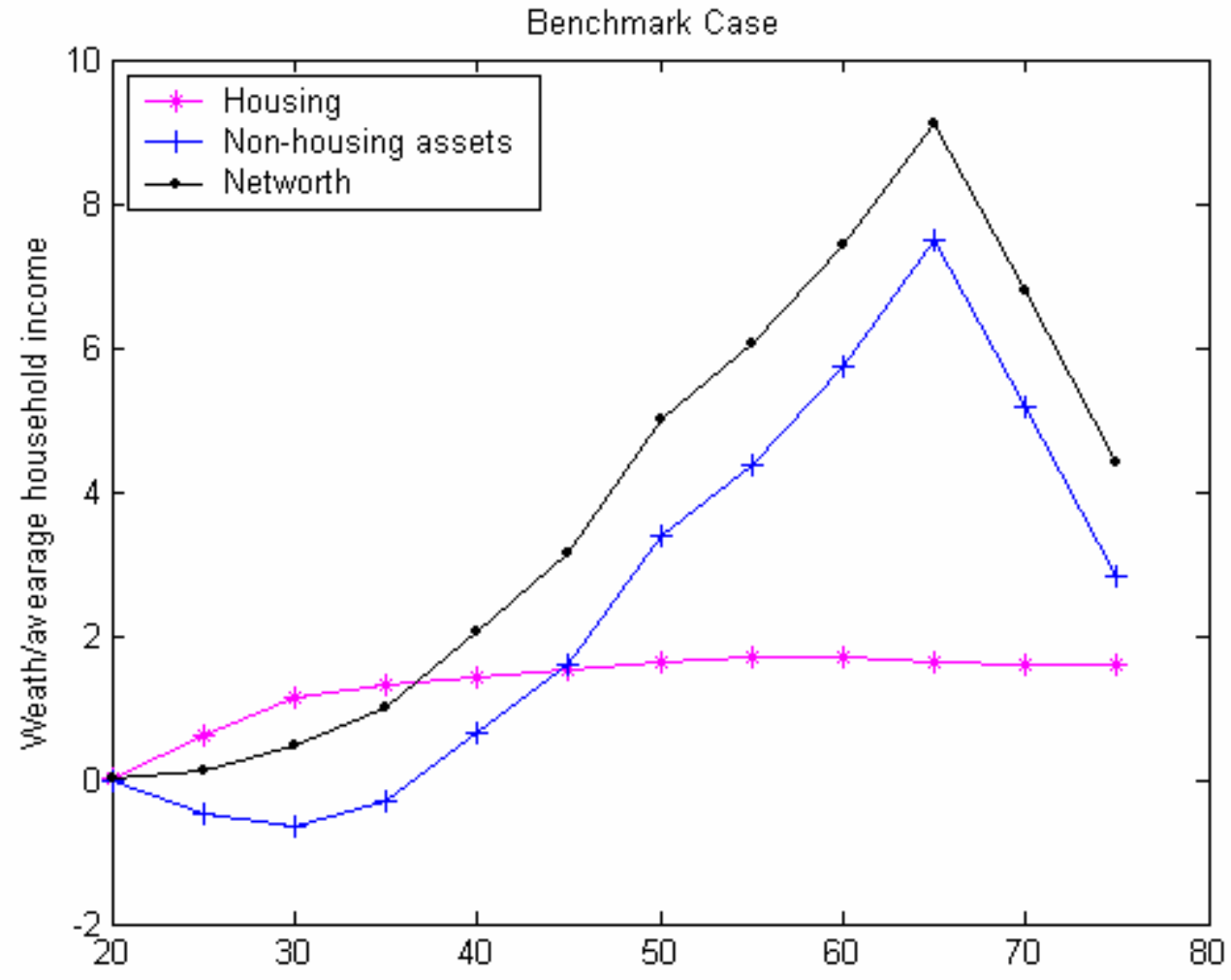

Figure 5.1: life cycle patterns of wealth composition (benchmark) 


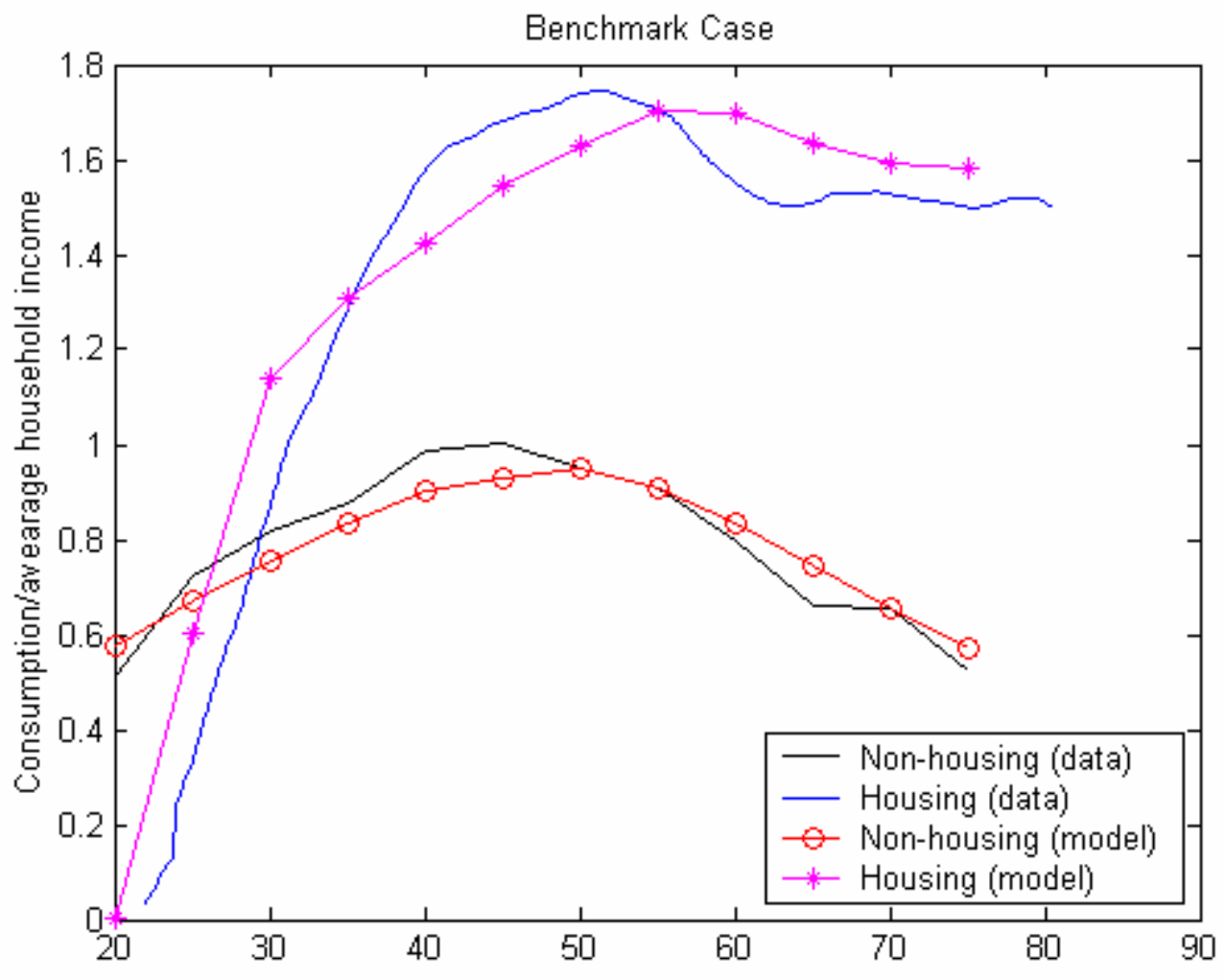

Figure 5.2: Life cycle patterns of housing and non-housing goods consumption (benchmark) 


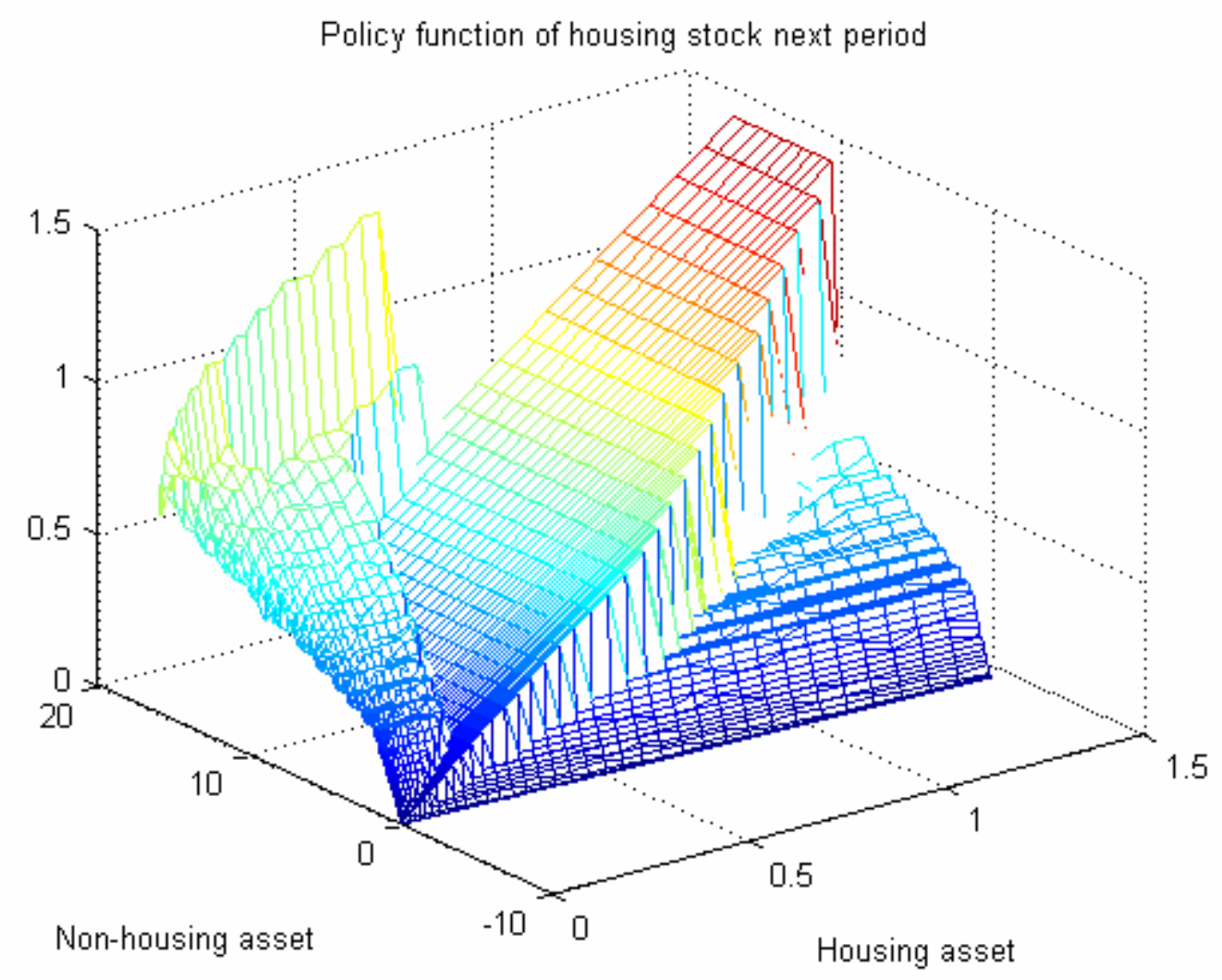

Figure 3: Policy Function of housing stock next period for 70-year-old 


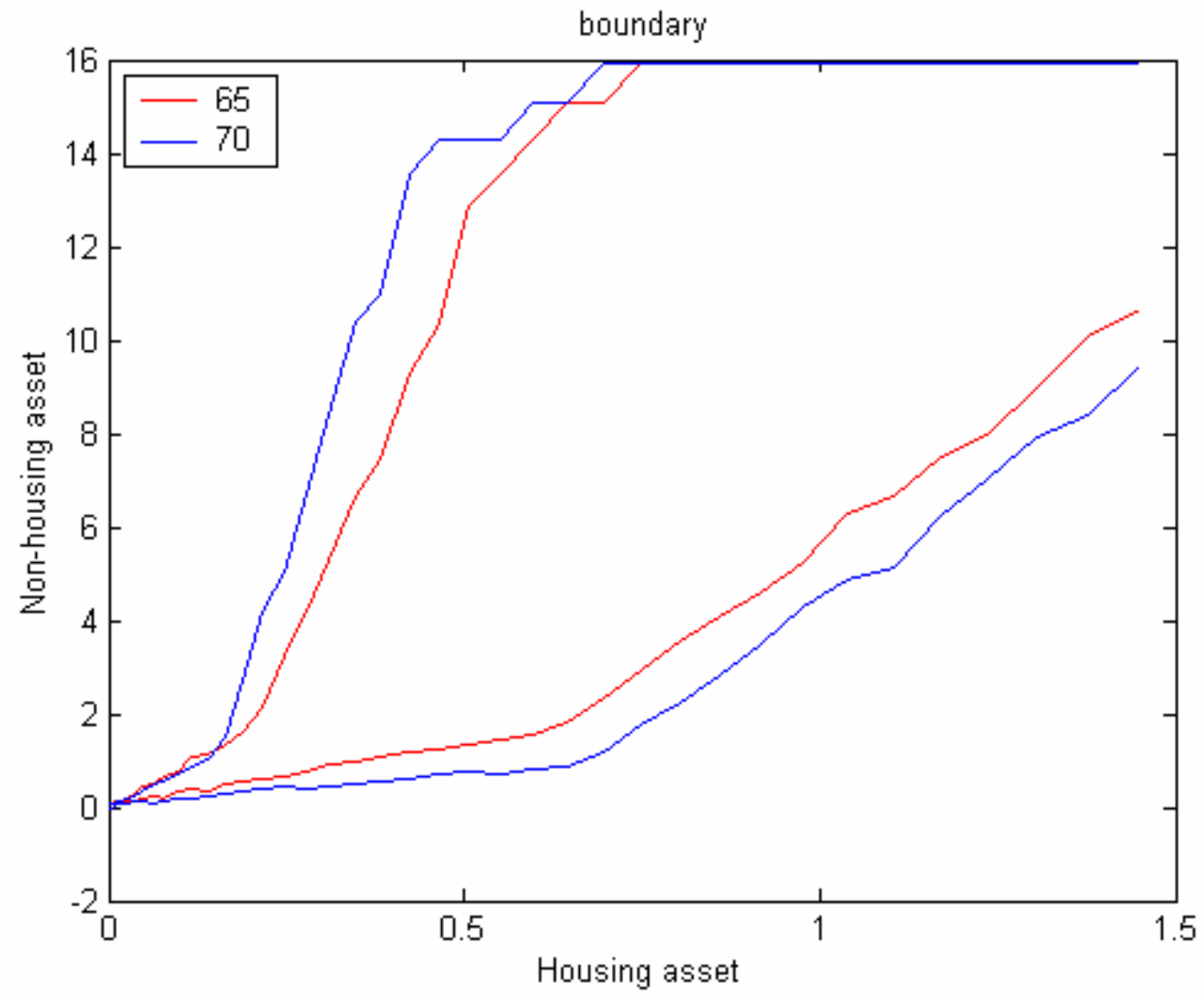

Figure 5.4: Boundaries of inactive zones 


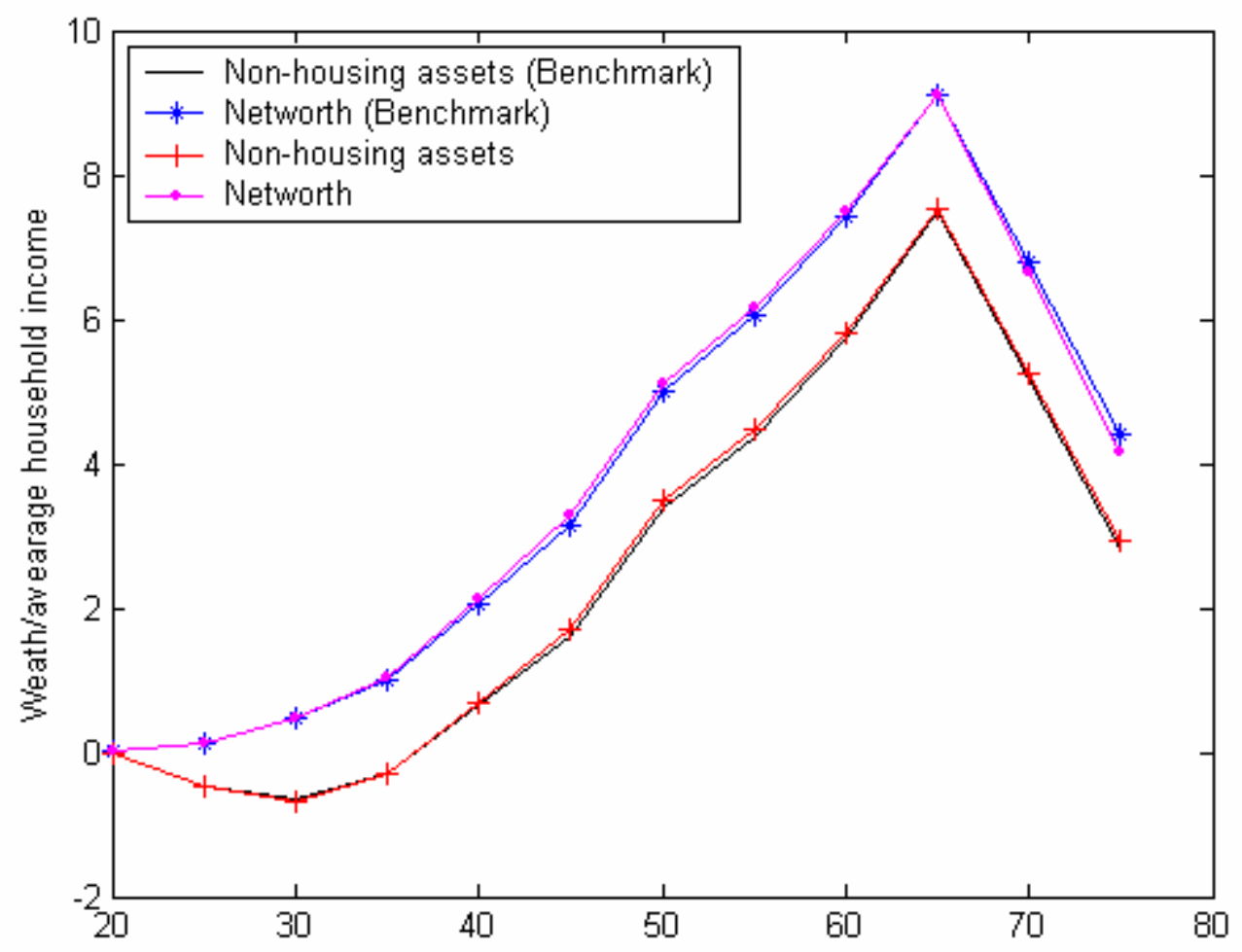

Figure 5.5: Life cycle patterns of wealth composition (No costs) 


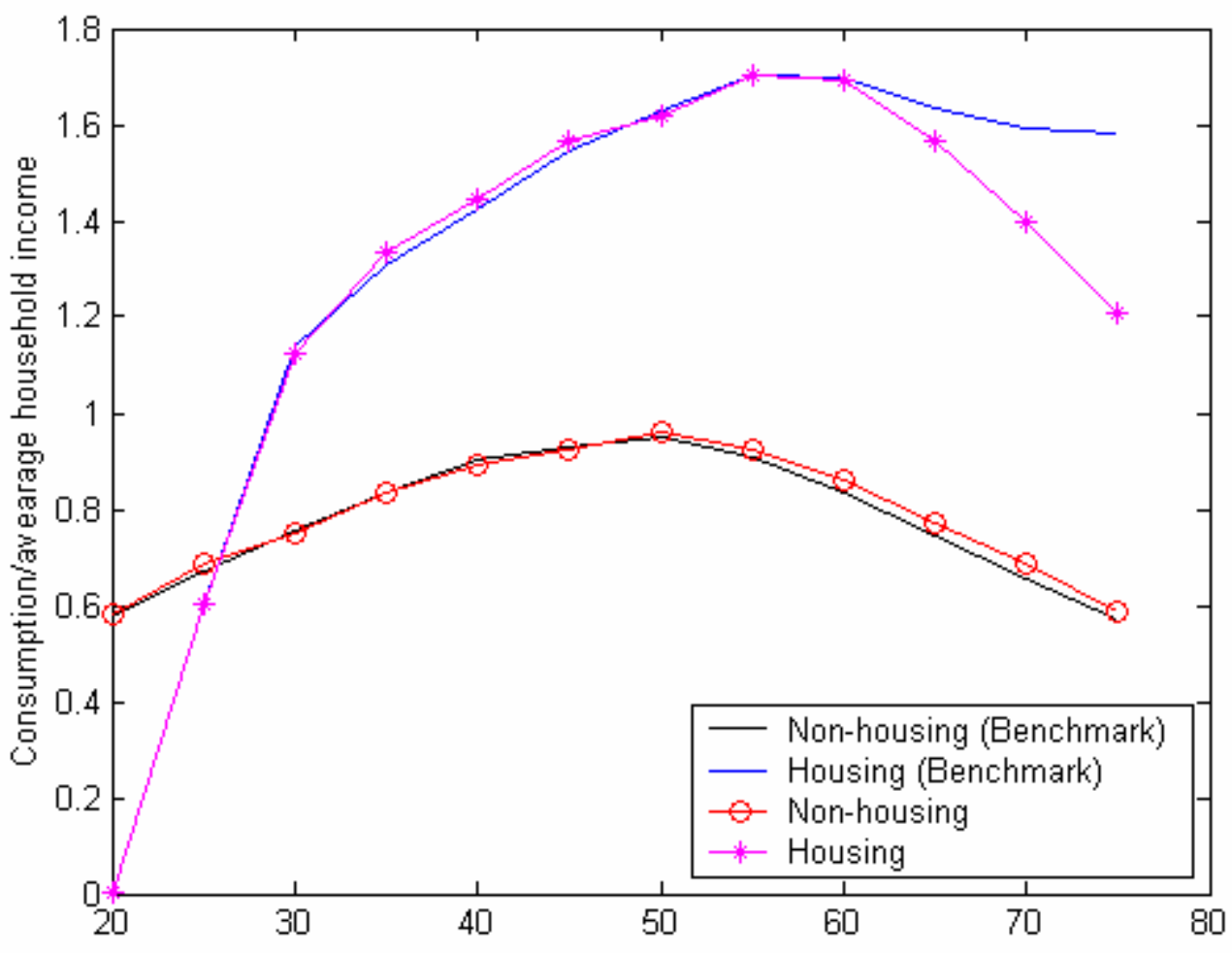

Figure 5.6: Life cycle patterns of housing and non-housing goods consumption (No costs) 


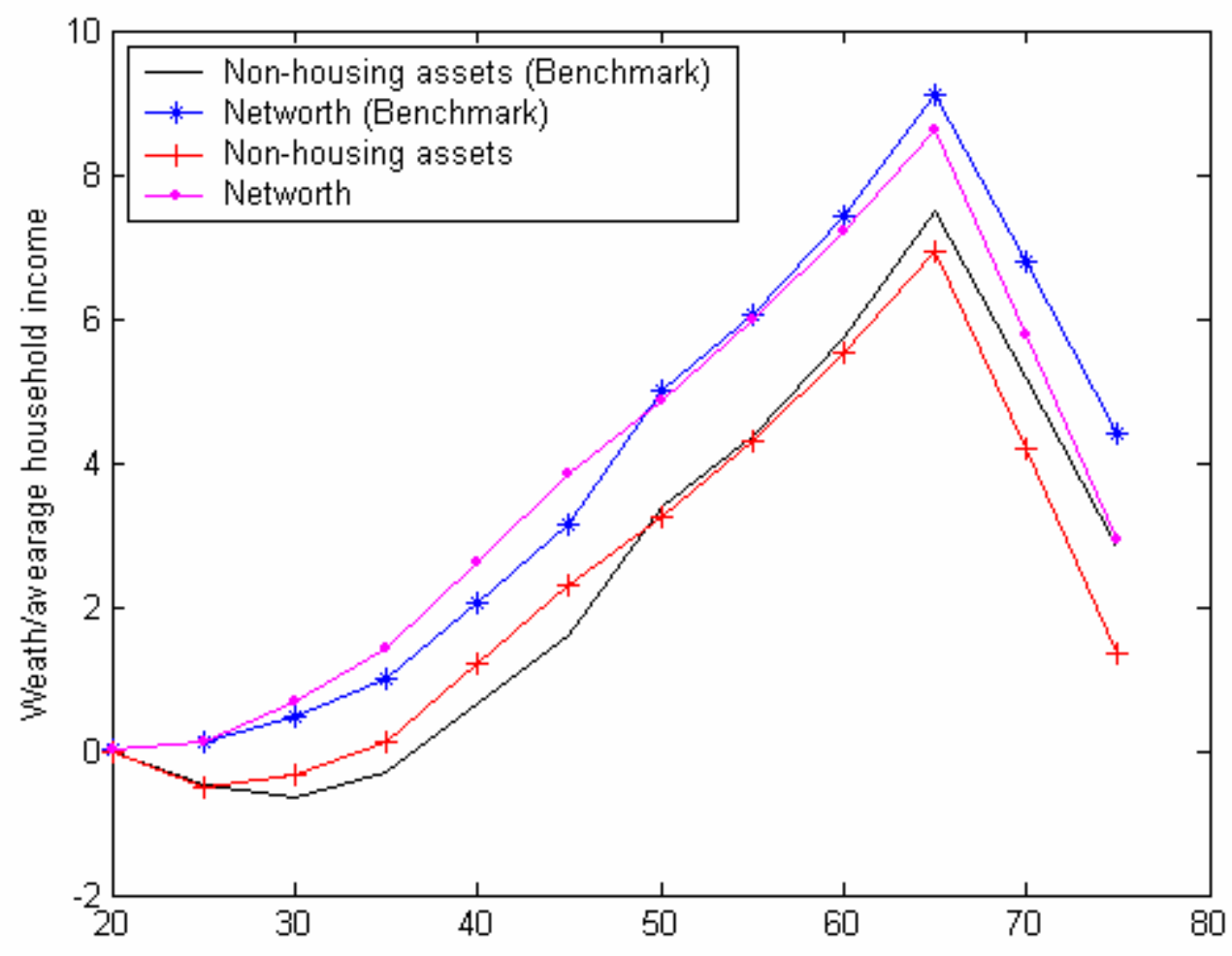

Figure 5.7: Life cycle patterns of wealth composition (No bequest motives) 


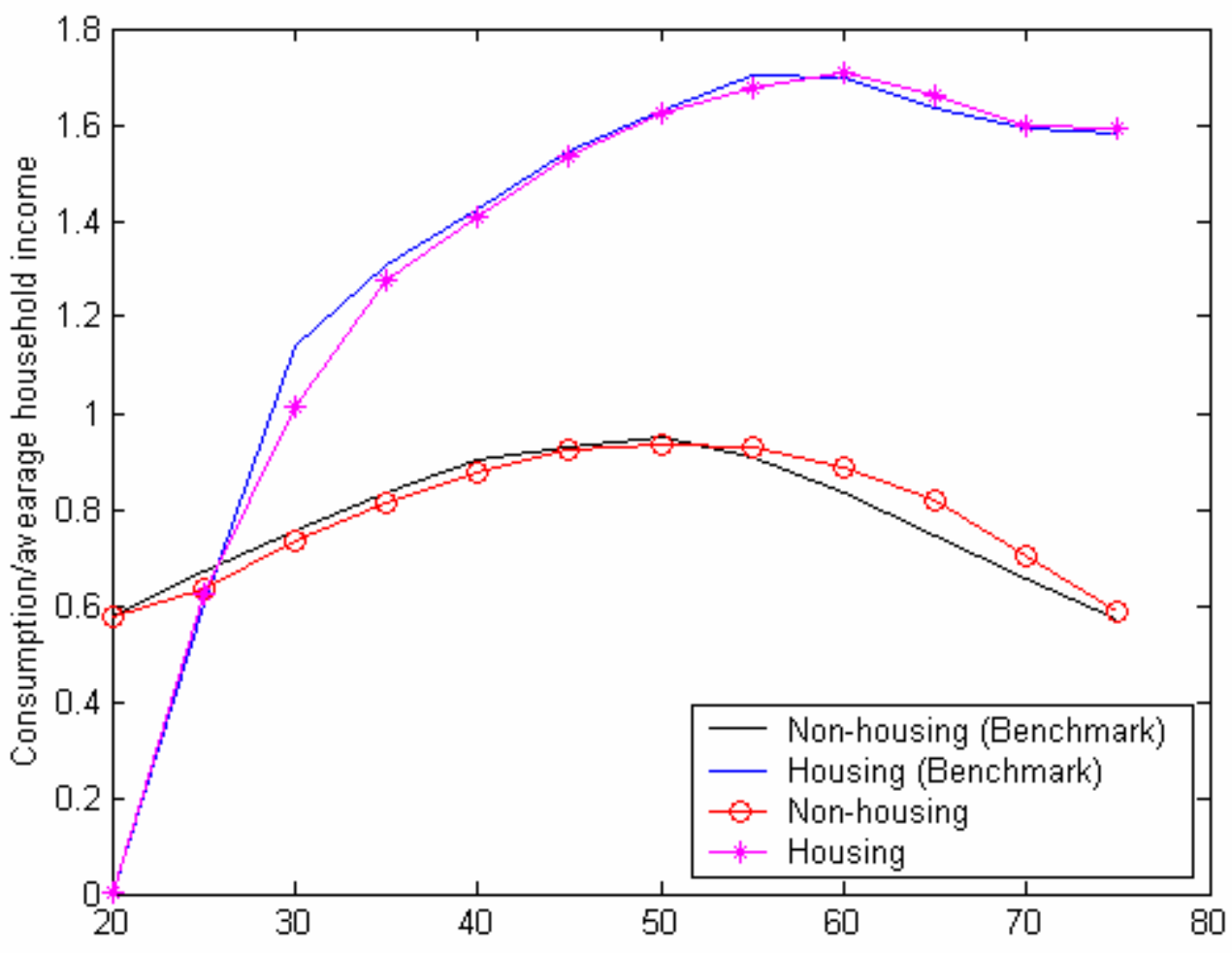

Figure 5.8: Life cycle patterns of housing and non-housing goods consumption (No bequest motives) 


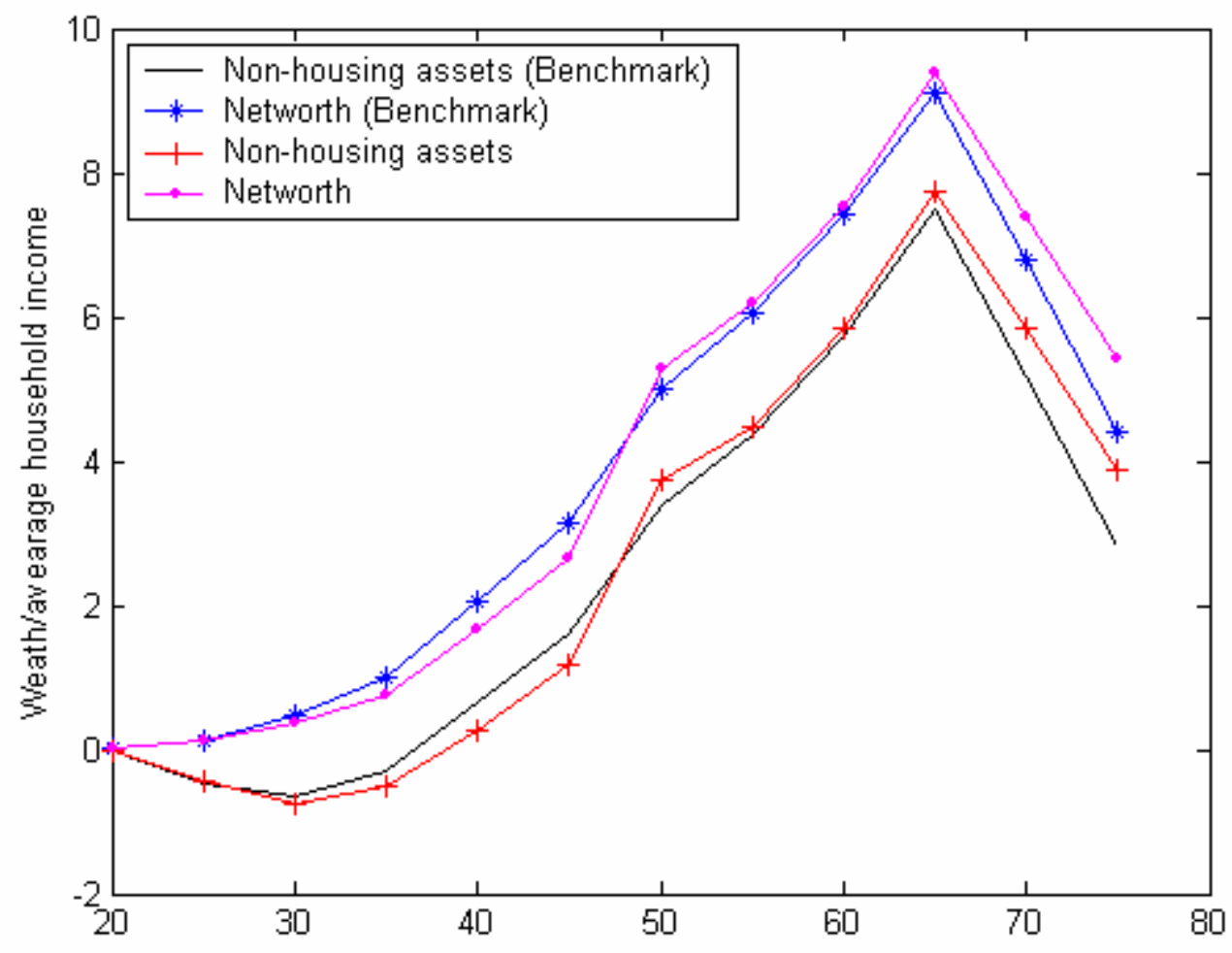

Figure 5.9: Life cycle patterns of wealth composition (High bequest motives) 


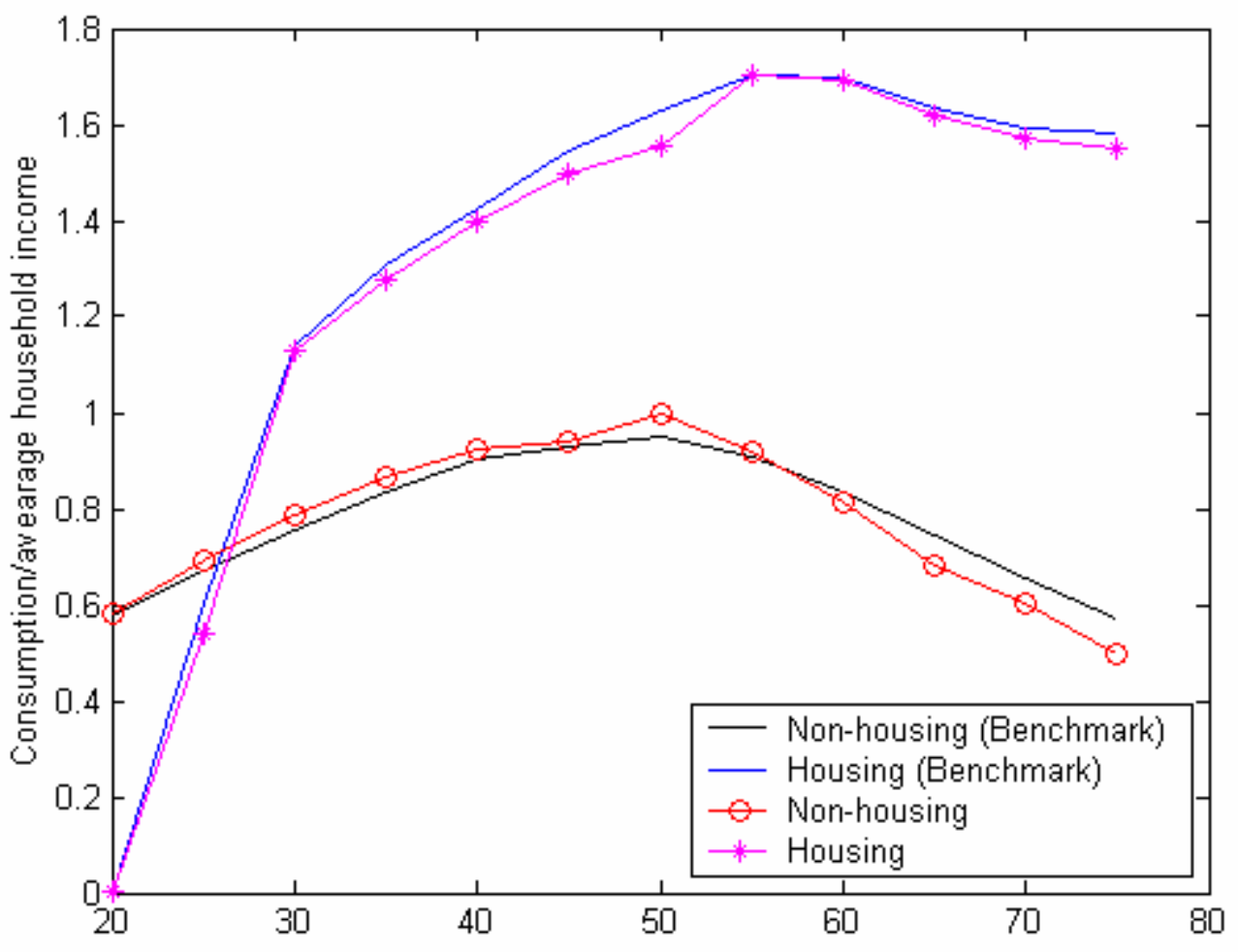

Figure 5.10: Life cycle patterns of housing and non-housing goods consumption (High bequest motives) 


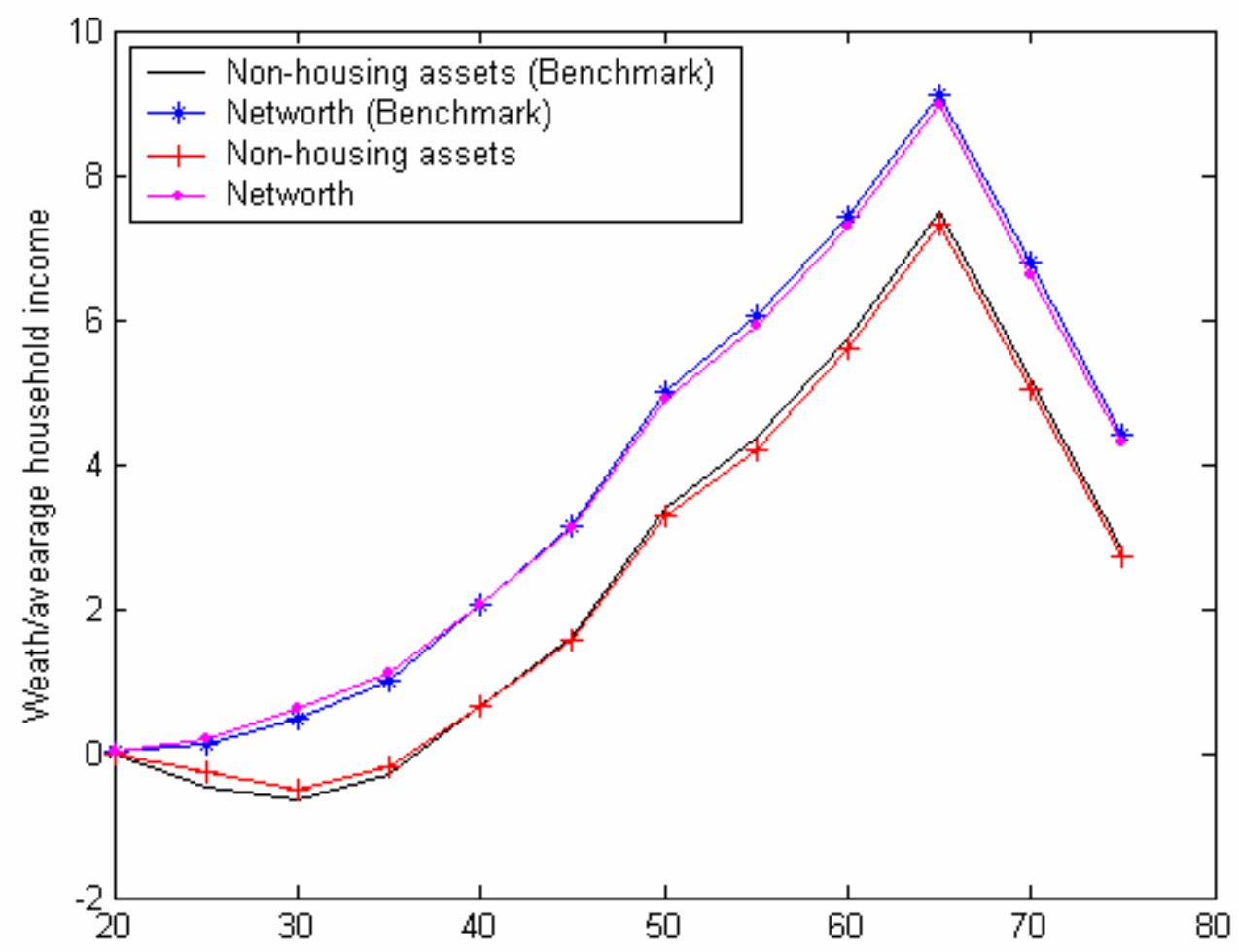

Figure 5.11: Life cycle patterns of wealth composition (High down payment) 


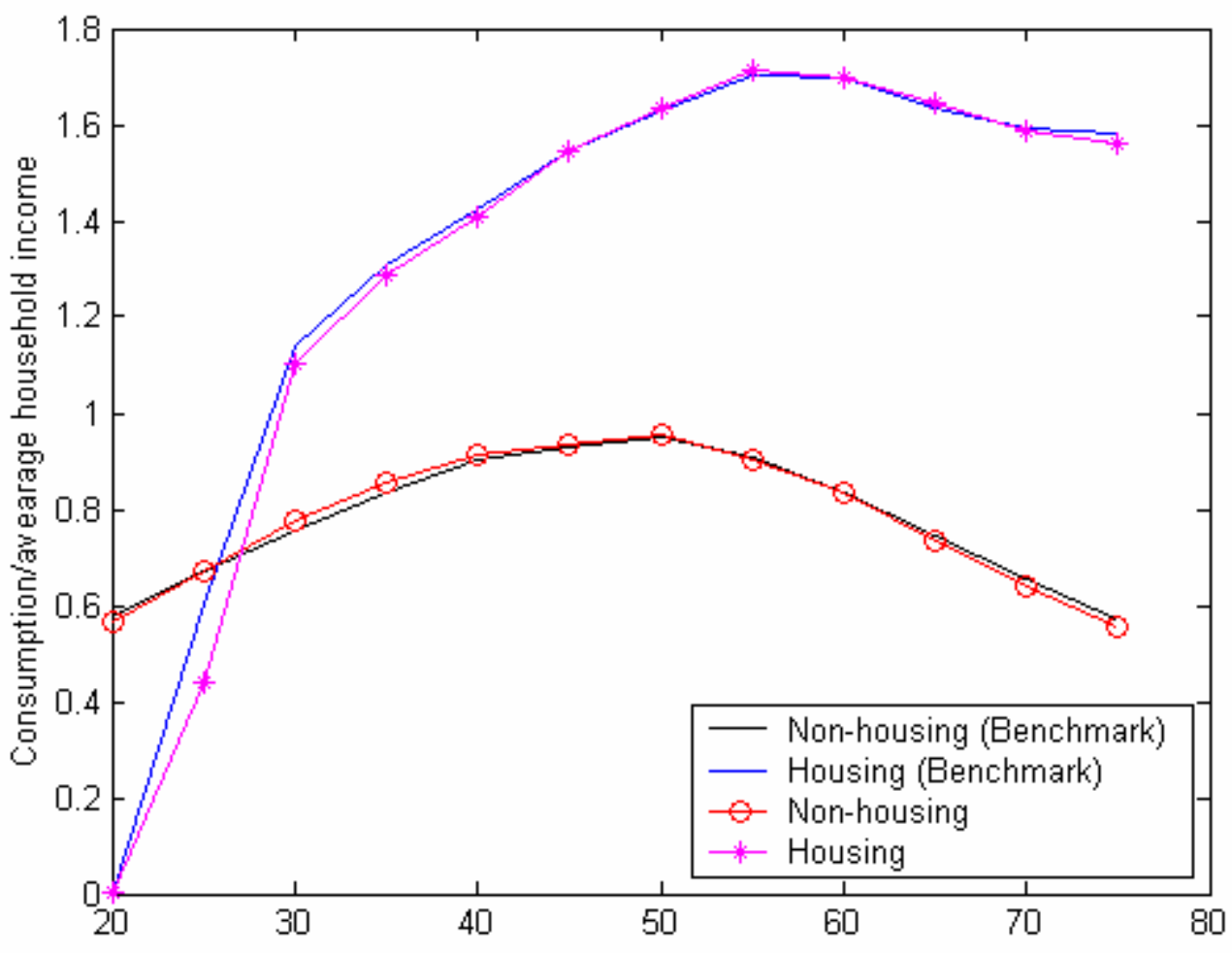

Figure 5.12: Life cycle patterns of housing and non-housing goods consumption (High down payment) 


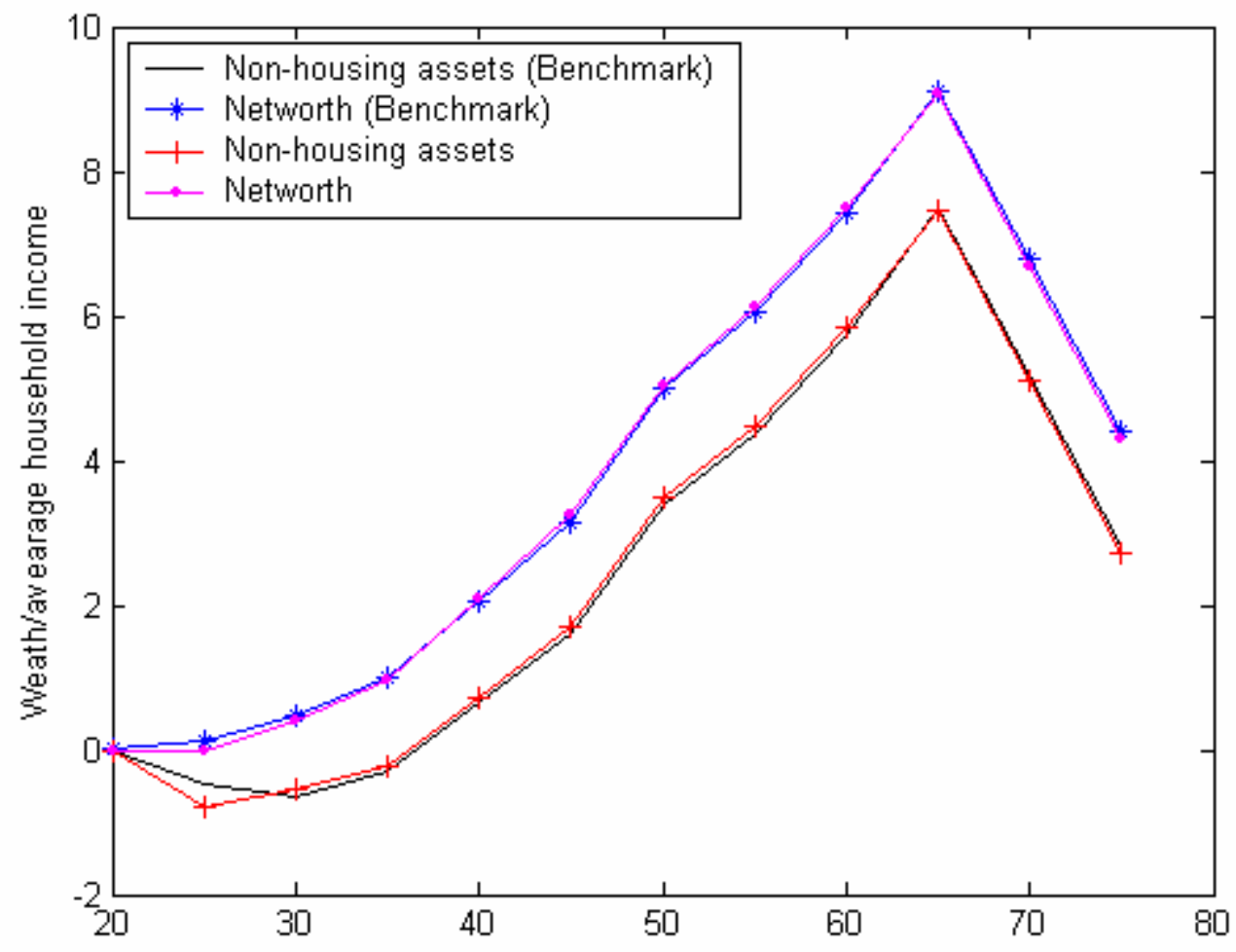

Figure 5.13: Life cycle patterns of wealth composition (No down payment) 


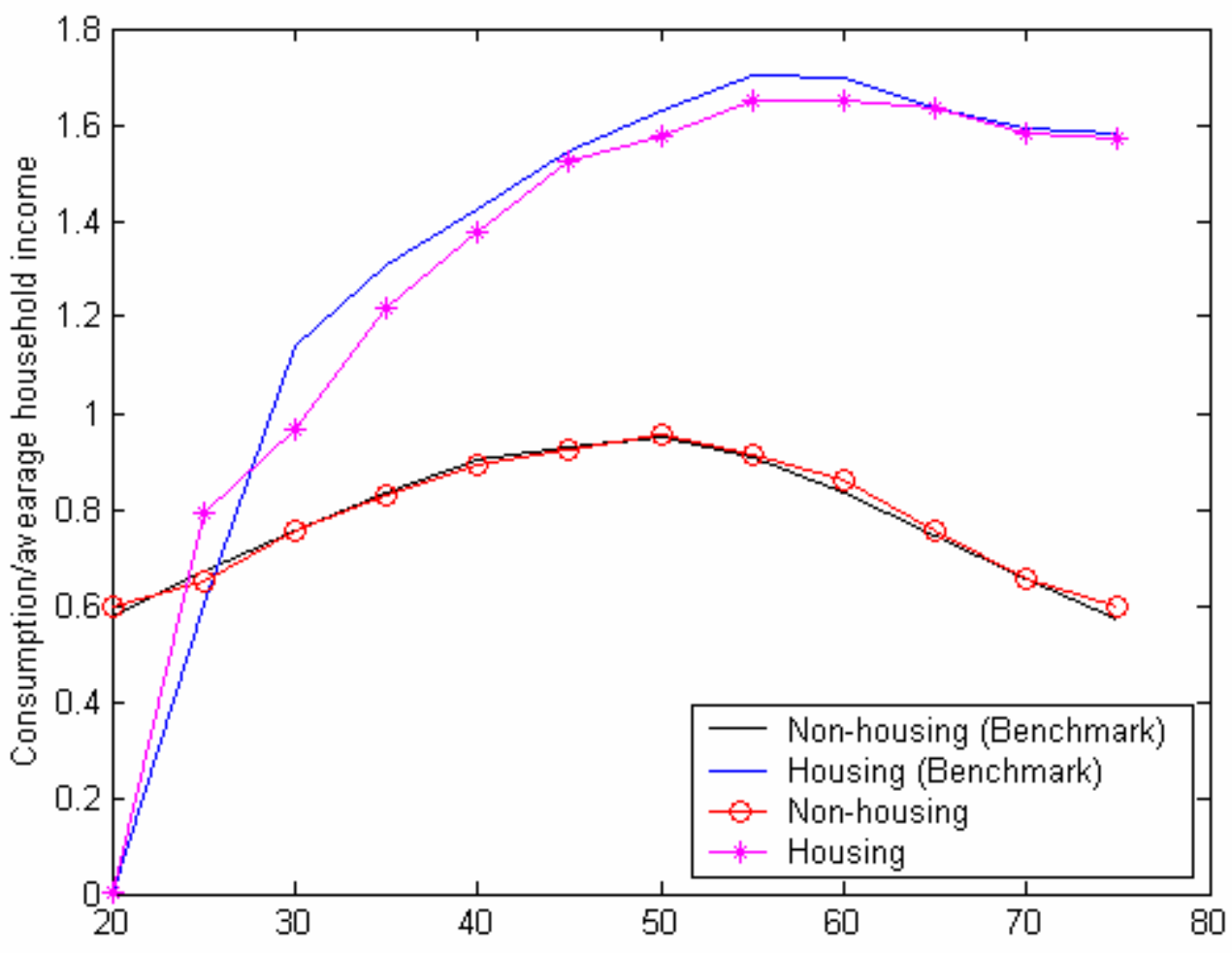

Figure 5.14: Life cycle patterns of housing and non-housing goods consumption (No down payment) 


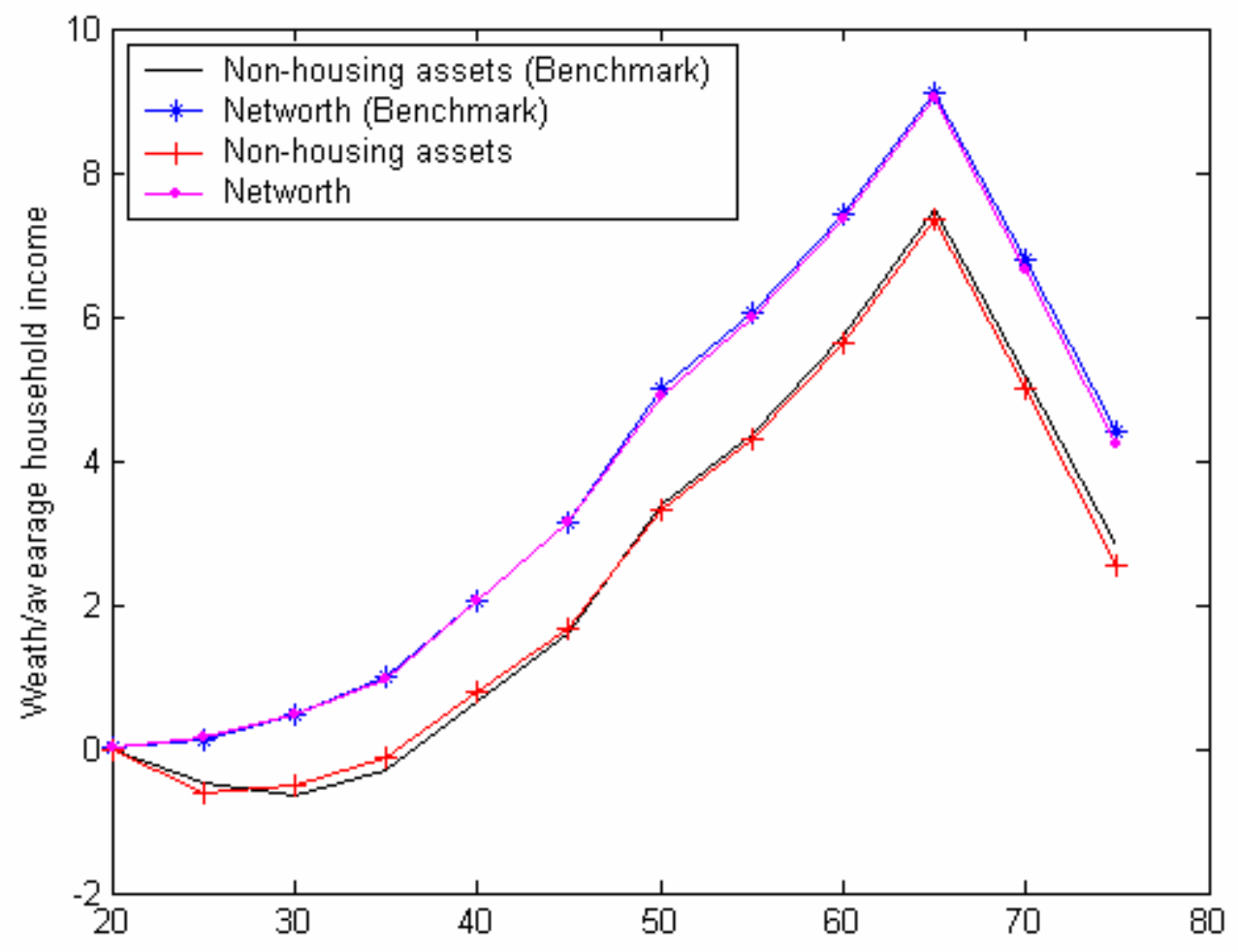

Figure 5.15: Life cycle patterns of wealth composition (High Elasticity) 


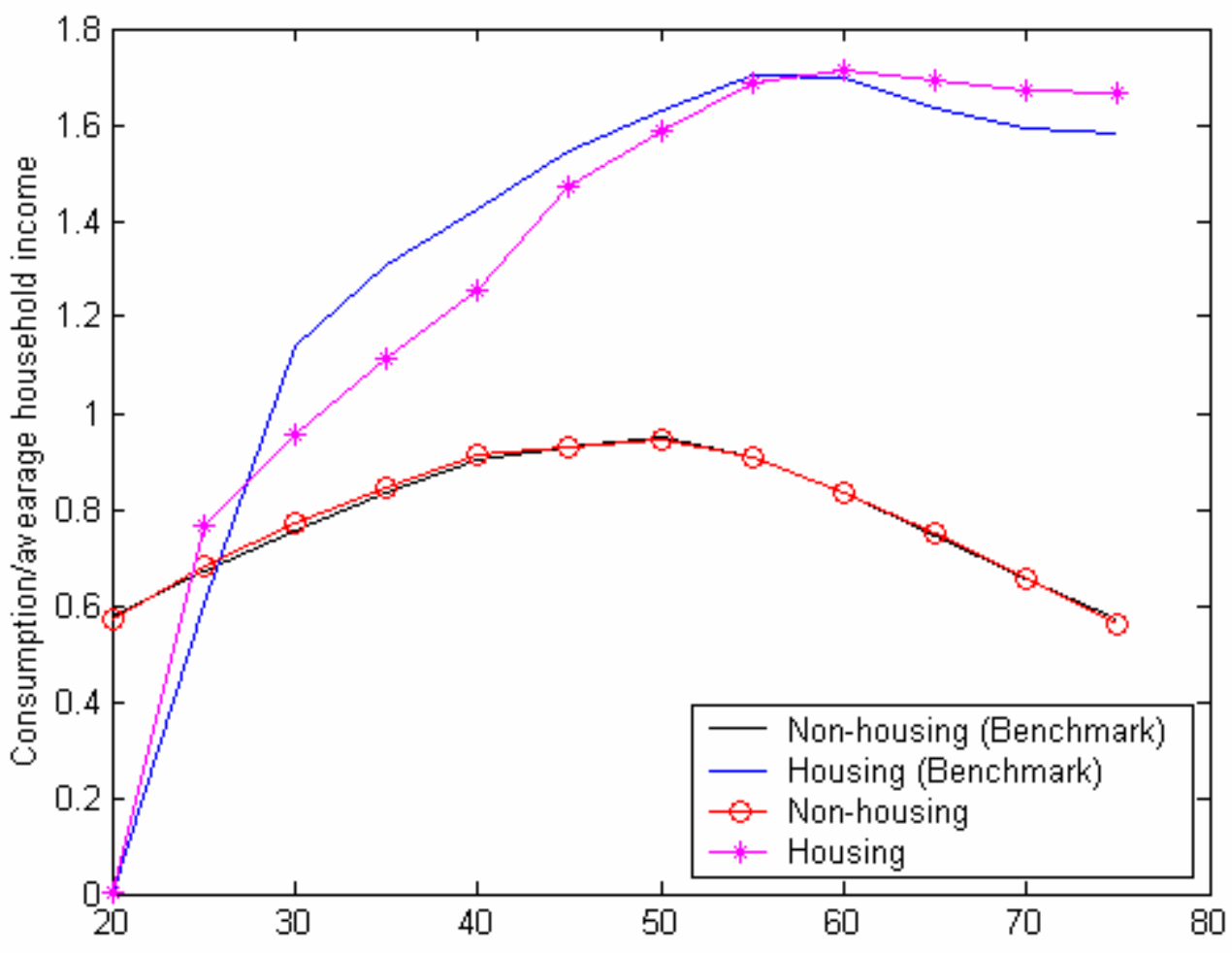

Figure 5.16: Life cycle patterns of housing and non-housing goods consumption (High Elasticity) 


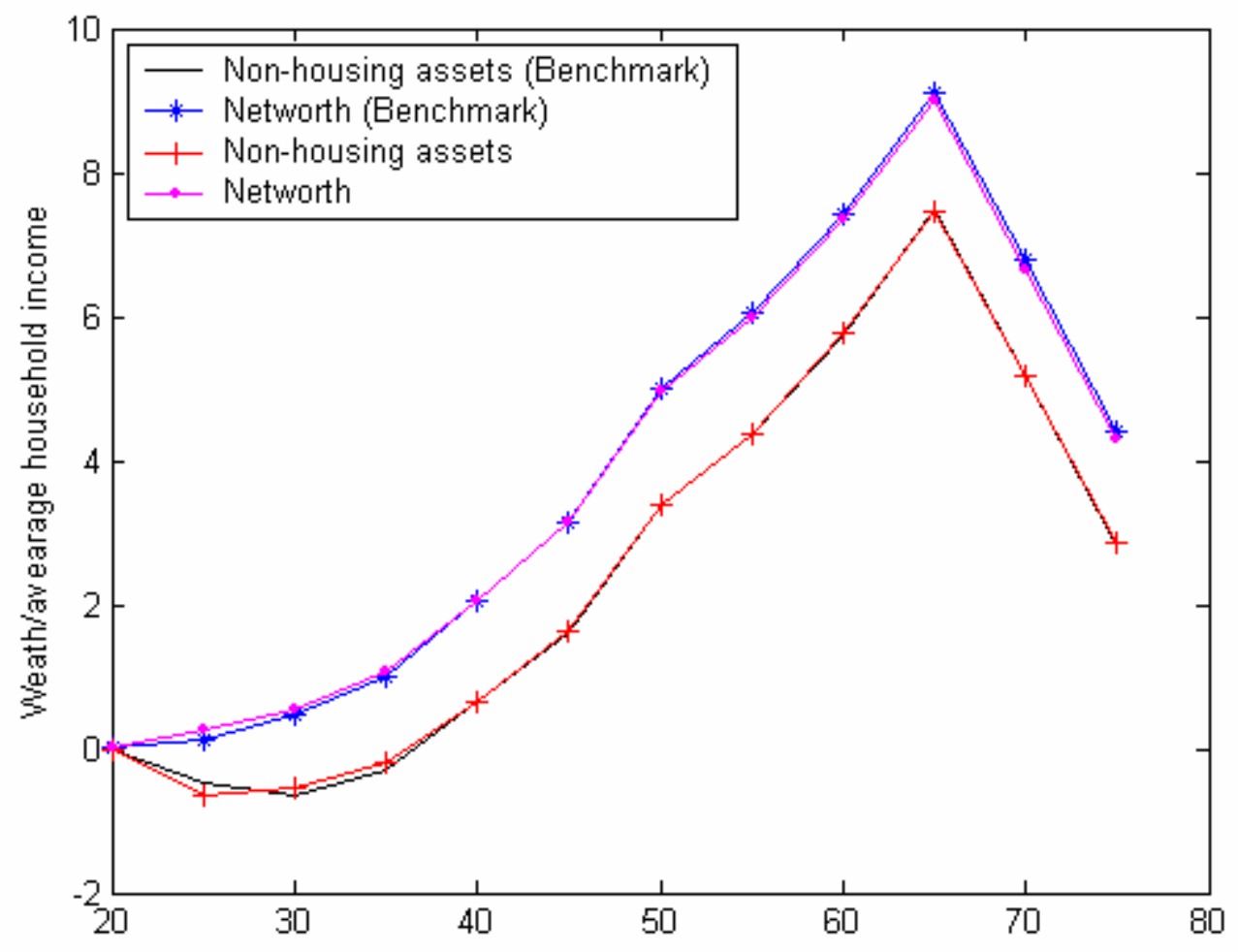

Figure 5.17: Life cycle patterns of wealth composition (Low Elasticity) 


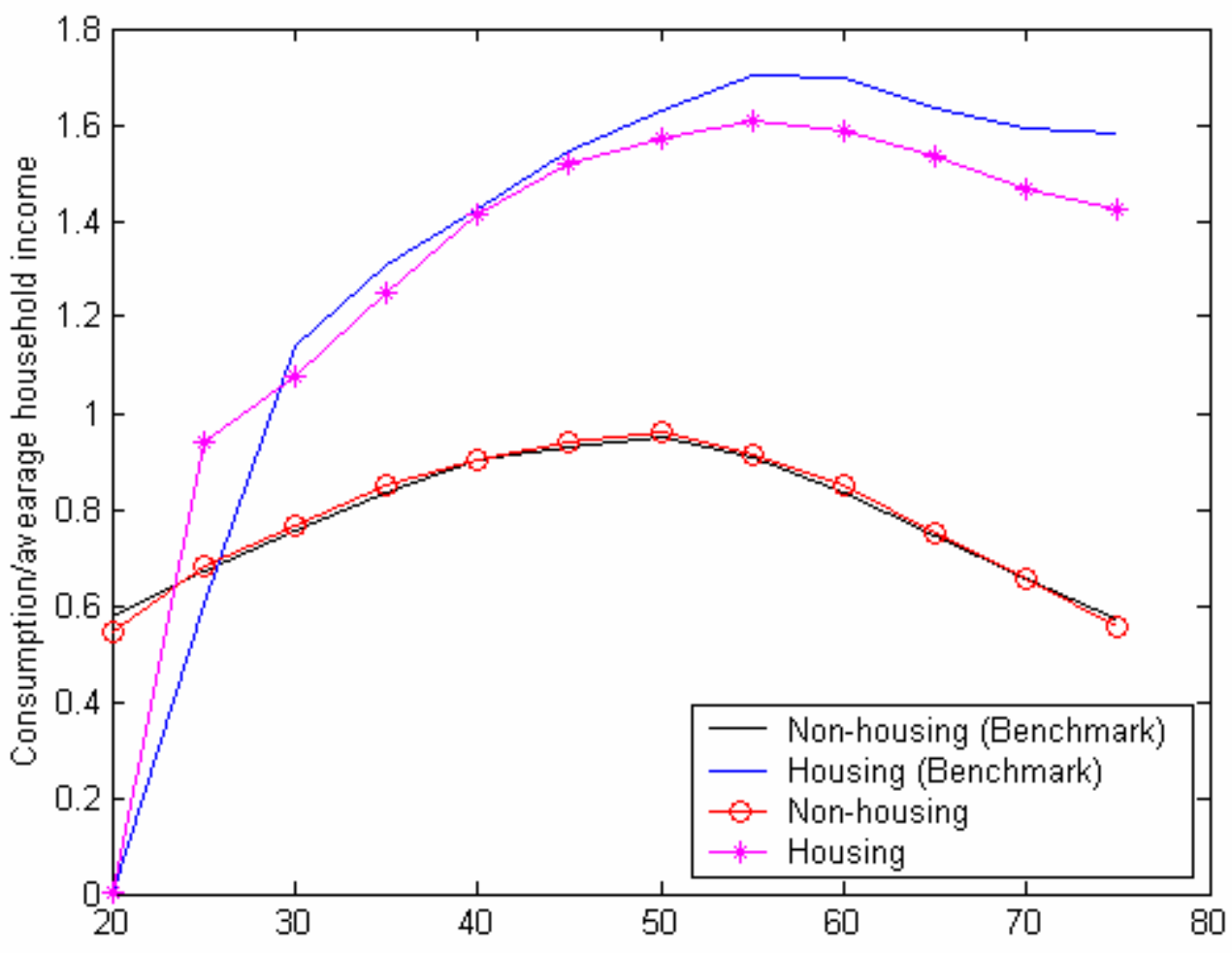

Figure 5.18: Life cycle patterns of housing and non-housing goods consumption (low Elasticity) 


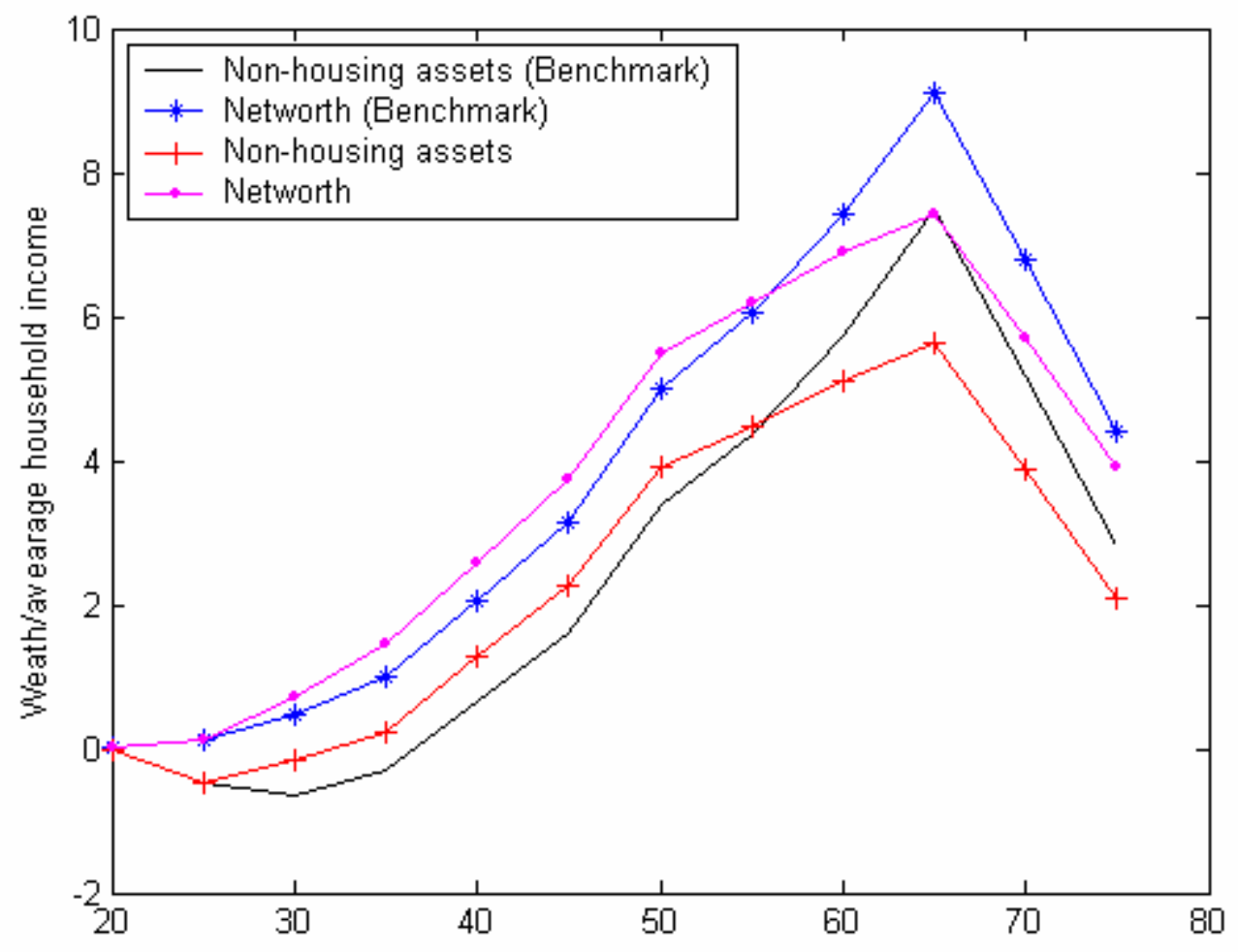

Figure 5.19: Life cycle patterns of wealth composition (Social Security) 


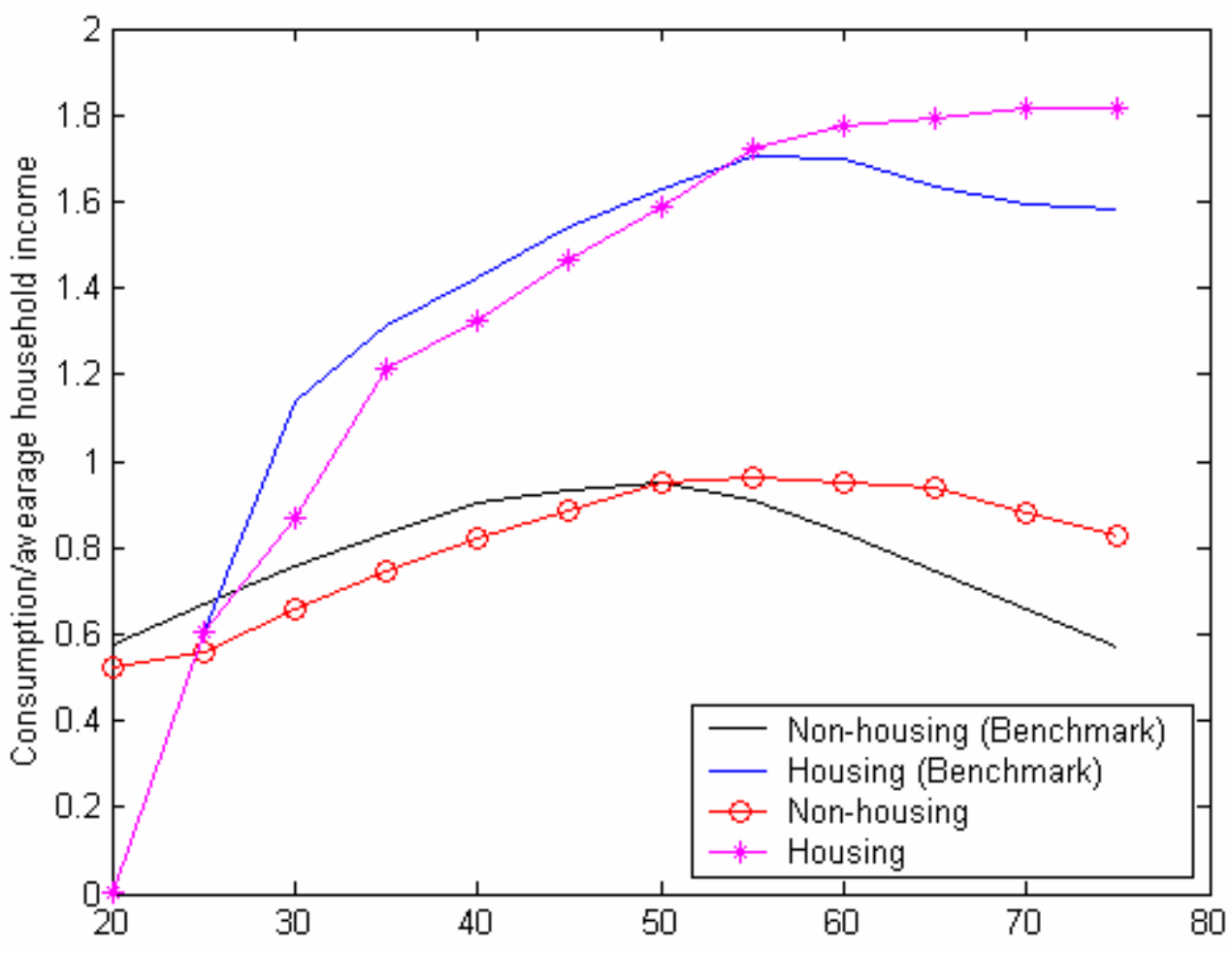

Figure 5.20: Life cycle patterns of housing and non-housing goods consumption (Social Security) 


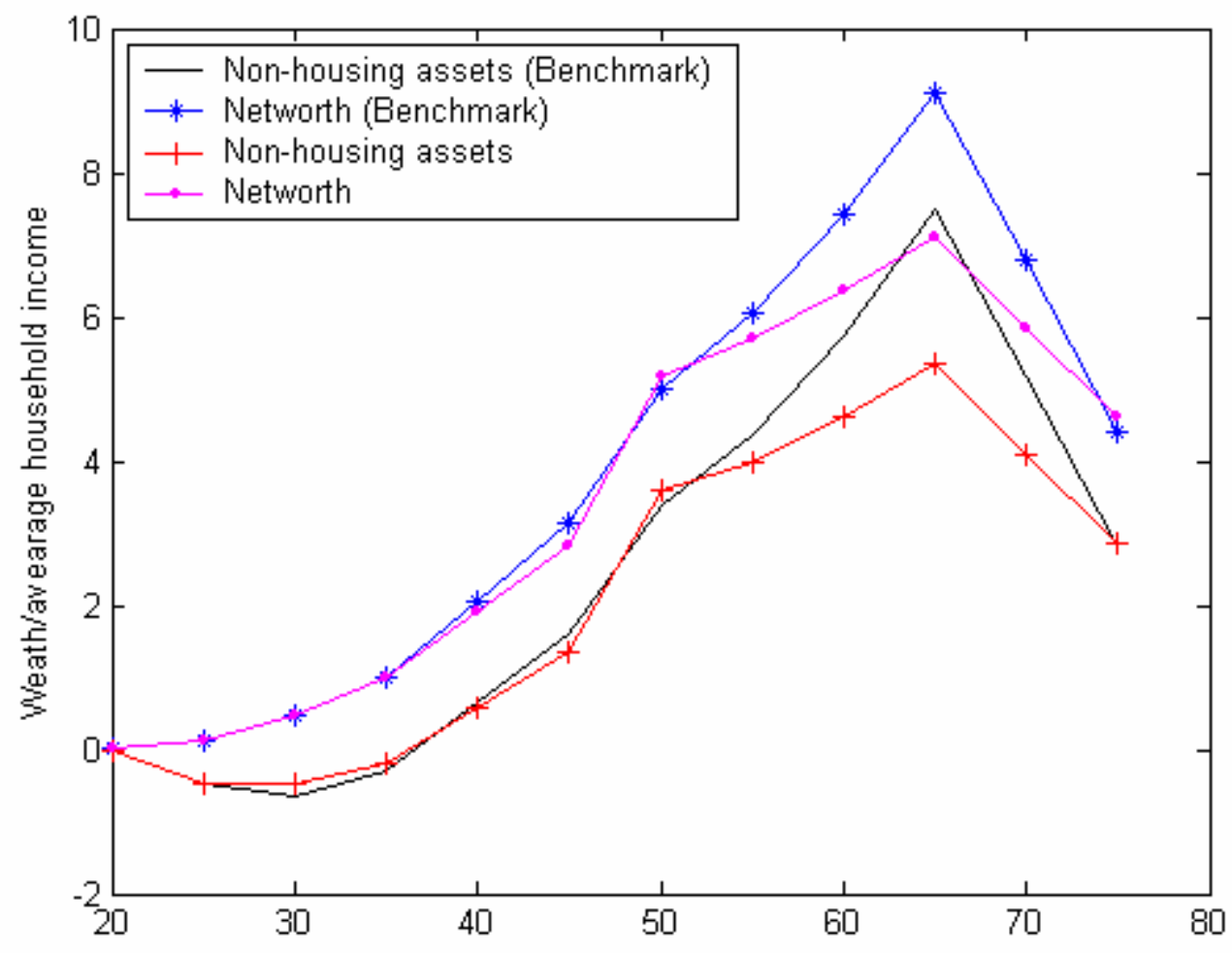

Figure 5.21: Life cycle patterns of wealth composition (Social Security, high bequest motive) 


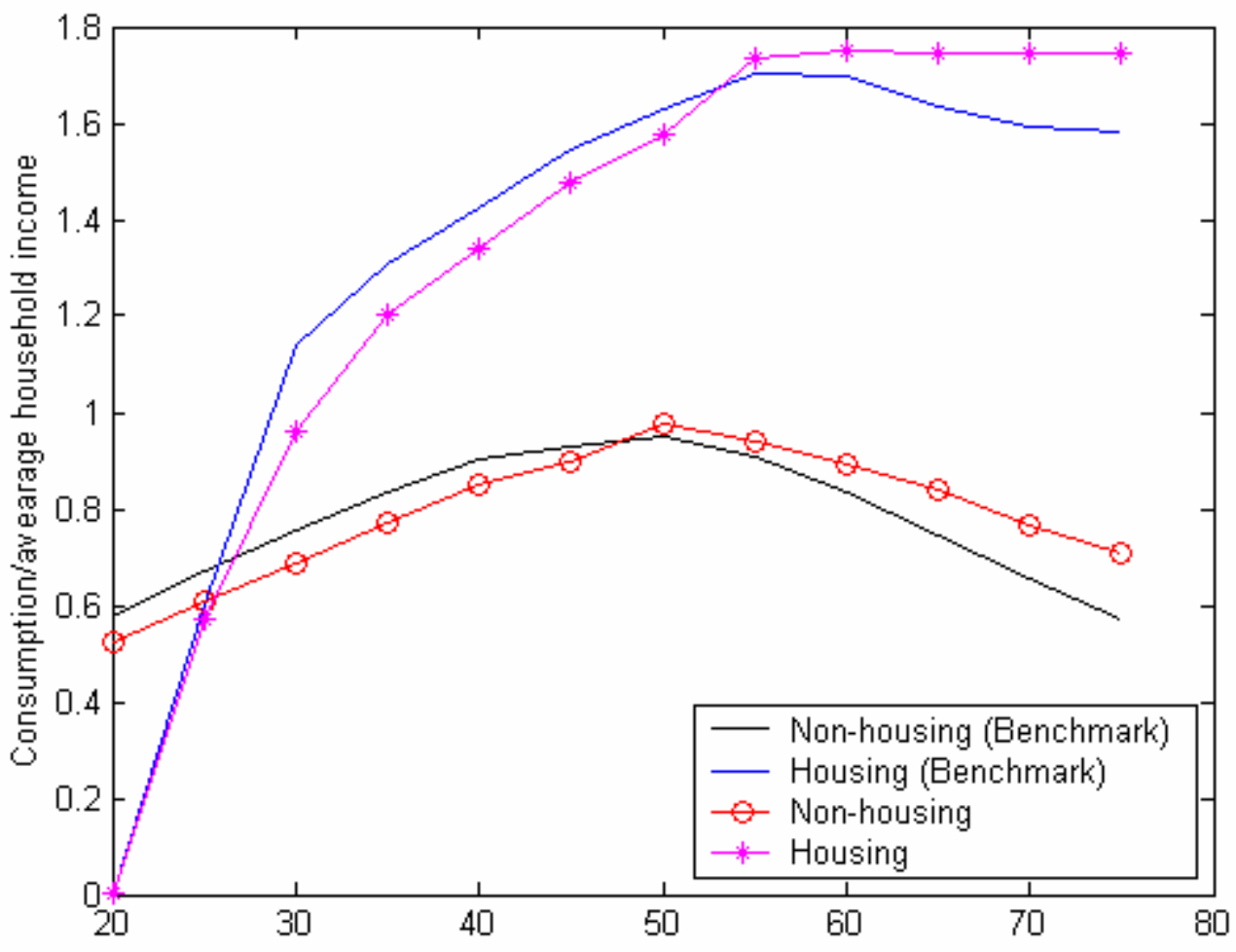

Figure 5.22: Life cycle patterns of housing and non-housing goods consumption (Social Security, high bequest motive) 